\title{
A novel murine model for non-alcoholic steatohepatitis developed by combination of a high-fat diet and oxidized low-density lipoprotein
}

\author{
Yimin ${ }^{1}$, Hiroaki Furumaki ${ }^{2}$, Shiho Matsuoka ${ }^{2}$, Toshihiro Sakurai ${ }^{2}$, Masashi Kohanawa ${ }^{1}$, Songji Zhao ${ }^{3}$, Yuji Kuge $^{4}$, \\ Nagara Tamaki ${ }^{3}$ and Hitoshi Chiba ${ }^{2}$
}

Non-alcoholic steatohepatitis (NASH) is the hepatic manifestation of metabolic syndrome that is characterized by steatosis, inflammation, and fibrosis, and may progress to cirrhosis and carcinoma. To investigate its pathogenic processes, we established a novel murine model for NASH by combination of a high-fat diet (HFD) and oxidized low-density lipoprotein (oxLDL). Mice that received HFD for 23 weeks showed hepatic steatosis, slight fibrosis, and a high level of lipid peroxidation compared with a regular diet (RD)-fed mice. Hepatic injury and elevated tumor necrosis factor (TNF)- $\alpha$ mRNA expression were also detected in these mice. Moreover, oxLDL administration to HFD-fed mice during weeks 21-23 not only aggravated hepatic steatosis, fibrosis, and lipid metabolism, but also resulted in intense inflammation, including severe hepatic injury and inflammatory cell infiltration, which are the typical histological features of NASH. Inflammation was accompanied by increased gene expression of TNF- $\alpha$ and interleukin (IL)-6. Additionally, the livers of RD-fed animals treated with oxLDL during weeks 21-23 were characterized by foamy macrophages and inflammatory cell infiltration along with an elevated IL-6 mRNA level. These results suggest that an increased oxidative state, including HFD-induced intracellular lipid peroxidation and its extracellular source from oxLDL, is the actual trigger for hepatic inflammation in which liver injury is mediated by TNF- $\alpha$ and inflammatory cell accumulation is dependent on IL-6. HFD and oxLDL also induced insulin resistance in mice; additionally, oxLDL downregulated insulin secretion. In this model, CD36 overexpression was observed in the hepatocytes of HFD-fed mice and those treated with HFD and oxLDL, and in the hepatic macrophages of RD-fed mice immediately after oxLDL treatment. In vitro experiments indicated a rapid and transient elevation of CD36 on macrophage plasma membrane in response to oxLDL. Our findings demonstrate that CD36 expressed on hepatocytes and hepatic macrophages mediates the pathophysiology of NASH. Laboratory Investigation (2012) 92, 265-281; doi:10.1038/labinvest.2011.159; published online 7 November 2011

KEYWORDS: CD36; high-fat diet; inflammation; mice; NASH; oxidized low-density lipoprotein

Non-alcoholic fatty liver disease (NAFLD) is recognized as the hepatic manifestation of obesity and metabolic abnormalities, the spectrum of which extends from simple hepatic steatosis through various degrees of inflammation to fibrosis. ${ }^{1,2}$ Non-alcoholic steatohepatitis (NASH), an important form of NAFLD, is characterized by liver steatosis, necrosis, inflammation, and fibrosis, and might result in further progression to cirrhosis and hepatocellular carcinoma. ${ }^{1,3}$ NASH is also universally accompanied by obesityassociated insulin resistance. ${ }^{2,4}$ To date, however, the etiopathogenesis of NASH and the mechanisms responsible for liver injury and disease progression remain incompletely understood. Studies of NASH have been hampered by the absence of a suitable experimental model. Although several animal models for NASH have been developed by genetic or nutritional manipulations, and have provided some findings, they fail to reflect the natural etiology and pathology of NASH in patients. For example, ob/ob mice that are genetically deficient in leptin develop spontaneous liver steatosis, but more significant injuries have not been observed. ${ }^{5}$ Supply

\footnotetext{
${ }^{1}$ Department of Advanced Medicine, Graduate School of Medicine, Hokkaido University, Sapporo, Japan; ${ }^{2}$ Department of Medical Laboratory Science, Faculty of Health Sciences, Hokkaido University, Sapporo, Japan; ${ }^{3}$ Department of Nuclear Medicine, Graduate School of Medicine, Hokkaido University, Sapporo, Japan and ${ }^{4}$ Central Institute of Isotope Science, Hokkaido University, Sapporo, Japan

Correspondence: Professor H Chiba, MD, PhD, Department of Medical Laboratory Science, Faculty of Health Sciences, Hokkaido University, Kita 12, Nishi 5, Sapporo 060-0812, Japan.

E-mail: chibahit@med.hokudai.ac.jp

Received 9 May 2011; revised 13 September 2011; accepted 22 September 2011
} 
of a methionine choline-deficient (MCD) diet to rodents leads to the induction of a benign model of NAFLD in which steatosis and inflammation are induced whereas fibrosis and lipotrophic factors remain undetected. ${ }^{6}$ Therefore, a suitable animal model is required to reflect the natural course and etiological background of NASH in humans.

The two-hit hypothesis proposed by Day and James ${ }^{7}$ states that development of NASH in humans is the consequence of sequential events. Hepatic steatosis induced by lipid accumulation in hepatocytes is recognized as the first hit, ${ }^{7,8}$ and is also identified as a critical prerequisite for the development of inflammation and an independent risk factor for liver fibrosis. ${ }^{9,10}$ The second hits are presumably considered to contribute to the progression from simple steatosis to steatohepatitis. This process represents a key step in the development of NASH. Although risk factors such as oxidative stress, mitochondrial injury, innate immunity, and proinflammatory cytokines have been implicated in the development of hepatic inflammation, ${ }^{11,12}$ the actual trigger for tissue inflammation and hepatocyte degeneration remains uncertain. Currently, increasing emphasis has been placed on oxidization of lipids and proteins as core events of inflammation associated with NASH. ${ }^{13,14}$ Oxidized lowdensity lipoprotein (oxLDL), the highly reactive form of LDL after lipid peroxidative modification, has many deleterious effects such as transformation of macrophages to foam cells ${ }^{15}$ induction of the production of numerous proinflammatory cytokines by vascular cells, ${ }^{16}$ and generation of cytotoxicity to induce cell death. ${ }^{17,18}$ OxLDL also initiates a dose-dependent increase in oxidative stress in cultured cells, including generation of reactive oxygen species and lipid peroxidation products, which is thought to be a crucial factor in the progression toward NASH. ${ }^{19,20}$ In clinical practice, high concentrations of circulating oxLDL are observed in patients with NASH. ${ }^{21}$ However, the precise relationship between oxLDL and the pathogenic processes of NASH remain obscure.

In the present study, we produced a novel experimental model for NASH in mice by chronic exposure to a high-fat diet (HFD) and intravenous administration of oxLDL in accordance with the two-hit hypothesis, and elucidated the effects of HFD and oxLDL on the pathogenesis of NASH. Increased oxidative stress in murine liver tissue, including intracellular lipid peroxidation induced by HFD and its extracellular source from oxLDL, are thought to have a crucial role in the pathogenesis of hepatic inflammation. In this study, we also investigated CD36 expression in different liver cells and its contribution to the pathophysiology of NASH. Our study provides additional insight into the progression of NASH.

\section{MATERIALS AND METHODS}

\section{Isolation of LDL and Preparation of oxLDL}

LDL was isolated from normal human plasma by a combination of sequential ultracentrifugation and gel filtration as described previously. ${ }^{22}$ EDTA-2Na (pH 7.4; $\left.0.27 \mathrm{mmol} / \mathrm{l}\right)$ was used throughout the separation procedures to avoid LDL oxidation. The LDL fraction was concentrated by ultra-filtration using an Amicon XM-50 membrane (Amicon, Palo Alto, CA, USA) and dialyzed against phosphate-buffered saline (PBS), and stored under nitrogen at $4{ }^{\circ} \mathrm{C}$ in the dark. Protein content was determined by a modified Lowry method. ${ }^{23}$ OxLDL was prepared by incubation of LDL in PBS with $\mathrm{CuSO}_{4}\left(0.8 \mathrm{~g} / \mathrm{l}\right.$ lipoprotein in $\left.20 \mathrm{~mol} / \mathrm{l} \mathrm{CuSO}_{4}\right)$ for $24 \mathrm{~h}$ at $37^{\circ} \mathrm{C}$ and was stored at $4{ }^{\circ} \mathrm{C}$ in the dark. The purity and charge of oxLDL were evaluated by examining electrophoretic migration in agarose gel. The degree of oxidation of oxLDL was determined by measuring the amount of thiobarbituric acid-reactive substances. ${ }^{24}$

\section{Animals and Diets}

Seven-week-old male C57BL/6J mice were purchased from Charles River Laboratories Japan (Yokohama, Japan) and received a regular diet (RD) (MF; Oriental Yeast Co. Ltd., Tokyo, Japan) during the initial 7 days of acclimatization. The animal protocol was approved by the Institutional Animal Care and Use Committee of Hokkaido University. After acclimatization, the mice were randomly divided into the following four groups: RD-fed mice (controls) were fed an RD for 23 weeks, with an intravenous injection of PBS ( $0.2 \mathrm{ml}$ per mouse, once every 3 days, eight times) from 21 weeks of the experiment; HFD-fed mice were fed an HFD (HFD-60; Oriental Yeast Co. Ltd.) for 23 weeks, with a PBS injection from 21 weeks; HFD + oxLDL mice were fed an HFD for 23 weeks, with an intravenous injection of oxLDL $(0.2 \mathrm{mg} / 0.2 \mathrm{ml}$ per mouse, once every 3 days, eight times) from 21 weeks; and RD + oxLDL mice were fed an RD for 23 weeks, with an oxLDL injection from 21 weeks. LDL, as control for oxLDL, was also injected into RD-fed mice during weeks $21-23(0.2 \mathrm{mg} / 0.2 \mathrm{ml}$ per mouse, once every 3 days, eight times). Additionally, to examine temporal changes in CD36 expression in hepatic macrophages in response to oxLDL, RD-fed mice were treated with oxLDL $(0.2 \mathrm{mg} / 0.2 \mathrm{ml}$ per mouse) for different durations. For all experiments, 3-4 animals were present per group. All mice were maintained in a temperature-controlled room with a 12-h light/dark diurnal cycle and had free access to food and water throughout the experiment. The compositions and calorific values of the experimental diets are presented in Table 1. The body weights and food intake of mice were measured under the experimental conditions.

\section{Preparation of Plasma and Liver Tissues}

Animals were fasted for $12 \mathrm{~h}$ and killed after they were subjected to the experimental conditions described above. Blood samples were obtained from jugular veins, and plasma was separated by centrifugation at $1200 \mathrm{~g}$ for $20 \mathrm{~min}$ at $4{ }^{\circ} \mathrm{C}$ and stored at $-80{ }^{\circ} \mathrm{C}$ until biochemical analysis. Murine livers were immediately removed and weighted, and fresh tissues were used for biochemical analysis and 
Table 1 Compositions and calorific values of the experimental diets

\begin{tabular}{lcccccc}
\hline & \multicolumn{2}{c}{$\mathrm{RD}(\mathrm{MF})$} & & \multicolumn{2}{c}{ HFD (HFD-60) } \\
\cline { 2 - 3 } \cline { 6 - 7 } & $\begin{array}{c}\text { Composition } \\
(\mathrm{g})\end{array}$ & $\begin{array}{c}\text { Calorie } \\
(\mathrm{kcal})\end{array}$ & & $\begin{array}{c}\text { Composition } \\
(\mathrm{g})\end{array}$ & $\begin{array}{c}\text { Calorie } \\
(\mathrm{kcal})\end{array}$ \\
\hline Protein & 23.1 & $92.4(25.6 \%)$ & & 23.0 & $91.6(18.1 \%)$ \\
Carbohydrate & 55.3 & $221.2(61.6 \%)$ & & 25.3 & $100.7(19.9 \%)$ \\
Fat & 5.1 & $45.9(12.8 \%)$ & & 35.0 & $313.7(62.0 \%)$ \\
Total calorie & & 359.0 & & & $506.0 / 100 \mathrm{~g}$
\end{tabular}

RNA studies. A portion of the liver was snap-frozen in liquid nitrogen for oil-red $\mathrm{O}$ staining, and the remaining liver tissues were fixed in 10\% neutral formalin for hematoxylin and eosin (H\&E) staining, Azan staining, and immunostaining.

\section{Analysis of Liver Architecture}

To clearly measure lipid accumulation in the liver of each mouse, frozen liver sections $(5 \mu \mathrm{m})$ were rinsed with distilled water, stained with $0.18 \%$ oil-red O (Sigma-Aldrich, MO, USA) with 60\% 2-propanol (Sigma-Aldrich) for $15 \mathrm{~min}$ at $37^{\circ} \mathrm{C}$, and finally counterstained with hematoxylin. The formalin-fixed specimens were dehydrated and embedded in paraffin blocks, and tissue sections of $2 \mu \mathrm{m}$ were stained with H\&E or Azan using standard techniques for liver morphological analysis. In each experiment, sections were made from three different areas of each organ and blindly scored by a single pathologist by light microscopy. The pathology evaluation was performed on the basis of steatosis, hepatocellular ballooning, lobular inflammation, and fibrosis according to the standard criteria for grading of NASH, with several modifications. ${ }^{25}$ The percentage of hepatic fat droplet area, which was quantified by using the ImageJ software, was used to evaluate steatosis in oil-red O-stained sections in the following manner: 0 , no steatosis; 1 , up to $33 \%$ steatosis; $2,33-66 \%$ steatosis; and 3, $>66 \%$ steatosis. Ballooning degeneration of hepatocytes was graded $0-2$ based on the number of balloon cells seen on H\&E-stained sections, as follows: 0 , no balloon cells; 1 , scattered balloon cells; and 2, panacinar balloon cells. Lobular inflammation was graded 0-3 based on inflammatory foci seen on H\&E-stained sections, as follows: 0 , no inflammation; $1,<2$ foci/ $\times 200$ field; $2,2-4$ foci $/ \times 200$ field; and $3,>4$ foci $\times 200$ field. Azan-stained sections were used for evaluation of fibrosis as follows: 0 , no fibrosis; 1 , pericellular and perivenular fibrosis; and 2 , focal bridging fibrosis.

\section{Immunohistological Analysis}

Paraffin sections were also used for immunohistochemistry of CD36; collagen type-1; CD3; F4/80, a surface marker of mouse macrophages; 8-hydroxy-2'-deoxyguanosine
(8-OHdG), a marker of oxidative DNA damage; and apoptosis. The sections were immunostained with rabbit antihuman CD36 (LifeSpan Biosciences Inc., WA, USA), rabbit anti-mouse collagen type-1 (AbD Serotec, UK), rabbit antihuman CD3 (DakoCytomation, Japan), rabbit anti-mouse F4/80 (Acris Antibodies Inc., CA, USA), or mouse antimouse 8-OHdG (Japan Institute for the Control of Aging, Japan), followed by application of the immunoperoxidase technique using the STAT-Q rapid IHC system (Innovex Biosciences, CA, USA). As a negative control, slides were incubated with normal rabbit IgG or mouse IgG (Santa Cruz Biotechnology Inc., CA, USA). The In situ Apoptosis Detection Kit (Takara Bio Inc., Japan) was used for detection of apoptotic hepatocytes. Stained regions were quantified using the ImageJ software and data are expressed as percentage of field area or percentage of the number of cells.

\section{Biochemical Assays}

The levels of alanine aminotransferase (ALT), free fatty acids (FFA), triglycerides (TG), cholesterol, glucose, and insulin in plasma were measured by using the Transferase CII-test, the Non-esterified fatty acids (NEFA) C-test, the TG E-test, the Cholesterol E-test, the Glucose CII-test (all from Wako Pure Chemical Industries, Tokyo, Japan), and the Mercodia Ultrasensitive Mouse Insulin ELISA Kit (Mercodia, Sweden), respectively, according to the manufacturer's instructions. Total hepatic lipids were extracted from liver homogenates by using methanol and chloroform according to a published method, ${ }^{26}$ and FFA, TG, and cholesterol contents were measured by the NEFA C-test, the TG E-test, and the Cholesterol E-test. Quantitative measurement of lipid peroxidation in the liver of each mouse was performed by using the Malondialdehyde Assay Kit (Northwest Life Science Specialties, LLC., WA, USA) according to the manufacturer's protocol.

\section{Isolation and Stimulation of Macrophages}

Peritoneal macrophages generated from RD-fed mice were used to investigate macrophage uptake of oxLDL in vitro. The cells were suspended in $0.83 \%$ ammonium chloride solution containing $10 \%$ (vol./vol.) Tris buffer ( $\mathrm{pH}$ 7.65) to lyse erythrocytes and resuspended in RPMI-1640 medium supplemented with $10 \%$ fetal bovine serum, $100 \mathrm{IU} / \mathrm{ml}$ penicillin, and $100 \mu \mathrm{g} / \mathrm{ml}$ streptomycin, as described previously. ${ }^{27}$ Macrophages at a density of $2 \times 10^{6}$ of were dispensed into culture dishes for total RNA isolation and confocal microscopic analysis. A total of $5 \times 10^{5}$ of the cells were seeded onto chamber slides for oil-red $\mathrm{O}$ staining using the protocol described above. After culture for $2 \mathrm{~h}$, floating cells were removed and attached macrophages were maintained in RPMI-1640 medium for $24 \mathrm{~h}$ before use.

Peritoneal macrophages were stimulated with $250 \mu \mathrm{g} / \mathrm{ml}$ oxLDL or left untreated, and then harvested for RNA isolation or stained at the indicated time points after stimulation. 
RNA Isolation and Quantitative Real-Time PCR Analysis Total RNA was isolated from mouse liver tissues or peritoneal macrophages using the Trizol reagent (Invitrogen, CA, USA) according to the manufacturer's protocol. A 2-ng weight of total RNA was converted into first-strand cDNA using the High-Capacity cDNA Reverse Transcription kits (Applied Biosystems, CA, USA). The cDNA was used for quantitative real-time PCR using the Power $2 \times$ SYBR Green PCR Master Mix and monitored on an ABI Prism 7000 sequence detection system (both from Applied Biosystems). The PCR conditions were $95^{\circ} \mathrm{C}$ for $10 \mathrm{~min}$ followed by 40 cycles at $95^{\circ} \mathrm{C}$ for $15 \mathrm{~s}$ and $60^{\circ} \mathrm{C}$ for $1 \mathrm{~min}$. The primer sequences of the selected genes are provided in Table 2. Relative gene expression versus untreated control was normalized by using the expression of the GAPDH housekeeping gene.

\section{Confocal Microscopic Analysis}

Peritoneal macrophages were incubated with rabbit antihuman CD36 (sc-9154; Santa Cruz Biotechnology Inc.) followed by an Alexa Fluor-488-conjugated chicken anti-rabbit IgG antibody (Molecular Probes, CA, USA). Immunostained cells were evaluated by laser-scanning confocal microscopy. Normal rabbit IgG was used for negative controls.

\section{Statistical Analysis}

All data are expressed as mean \pm s.d. Significant differences between values in the experimental and control groups were calculated by Student's $t$-tests. $P$-values $<0.05$ were considered statistically significant.

\section{RESULTS}

Effects of HFD, oxLDL, and Combination on Obesity and Liver Injury in Mice

We first studied the contributions of HFD and oxLDL to liver morphological changes in each mouse group. RD-fed mice showed a normal-sized liver, whereas hepatomegaly and pale color were observed in HFD-fed and HFD + oxLDL mice but not in RD + oxLDL mice (Figure 1a). Despite similar energy intake in the four mouse groups under the experimental conditions, the HFD-fed and HFD + oxLDL groups showed obesity and relative liver weight gain (liver weight/body weight) after 23 weeks compared with control RD-fed mice (Table 3). Concomitantly, elevated plasma levels of ALT, a marker of liver injury, were detected in the HFD-fed and HFD + oxLDL groups (4.52- and 6.94-fold versus RD-fed mice, respectively; $P<0.001)$ and this increase was more pronounced in HFD + oxLDL mice than in HFD-fed mice $(P<0.001)$ (Figure 1b). We also performed immunohistochemical analysis of hepatic apoptosis, which has emerged as one of the key pathways of liver injury in patients with NASH. ${ }^{1}$ A mild hepatic apoptosis was observed in the HFD-fed group, and the hepatic apoptosis level was significantly higher in the HFD + oxLDL group than in the HFD-fed and RD-fed groups (Figure 1c). There was no

Table 2 Primers used for quantitative real-time PCR

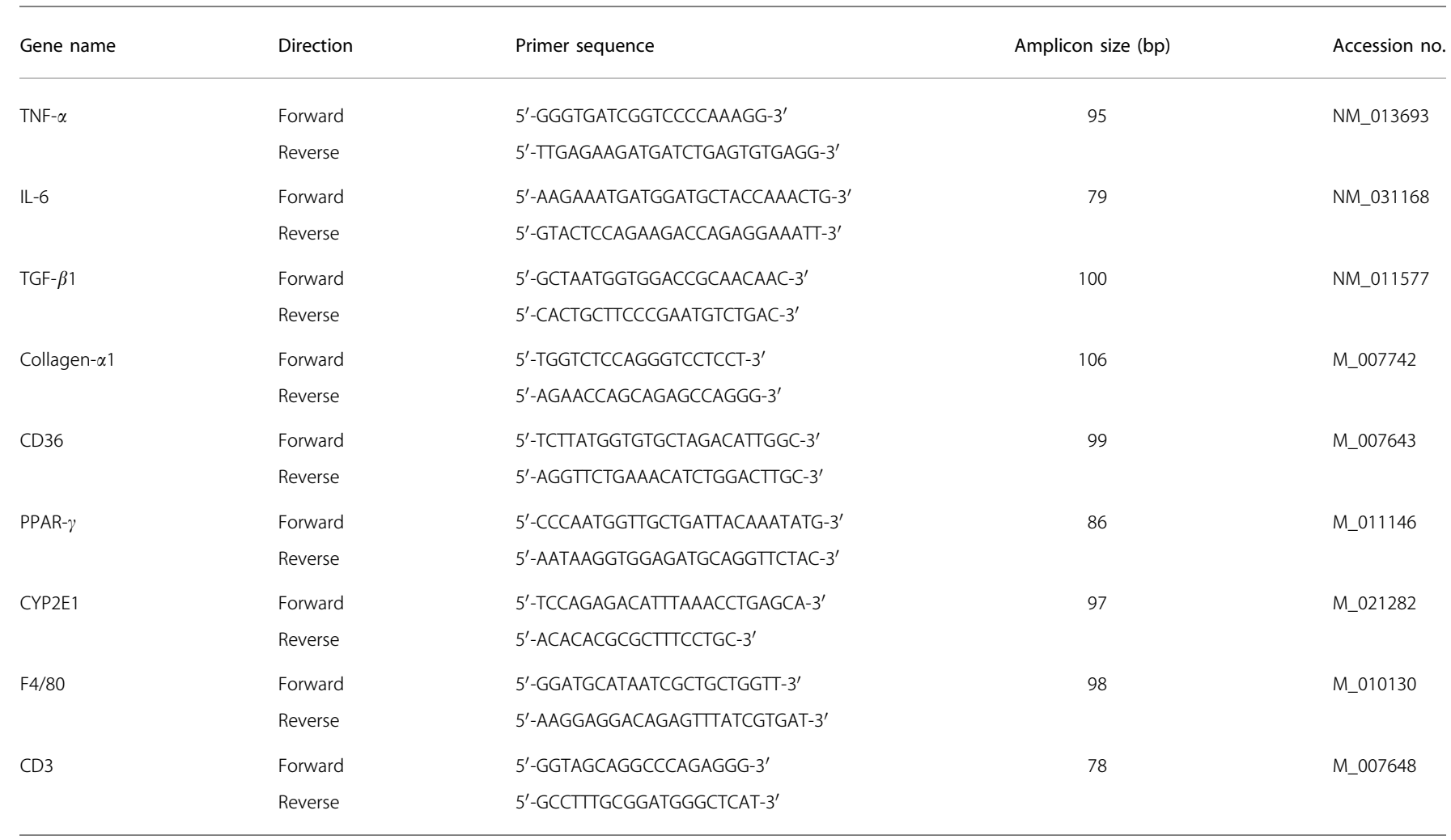


a

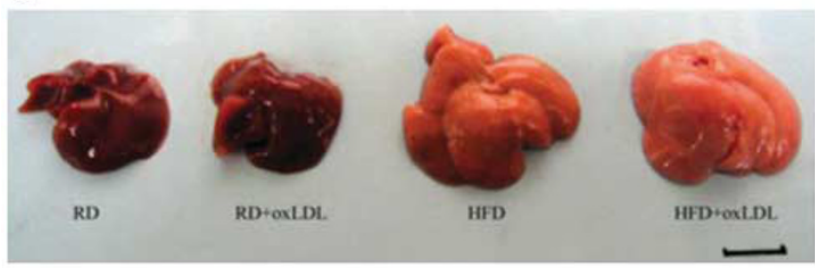

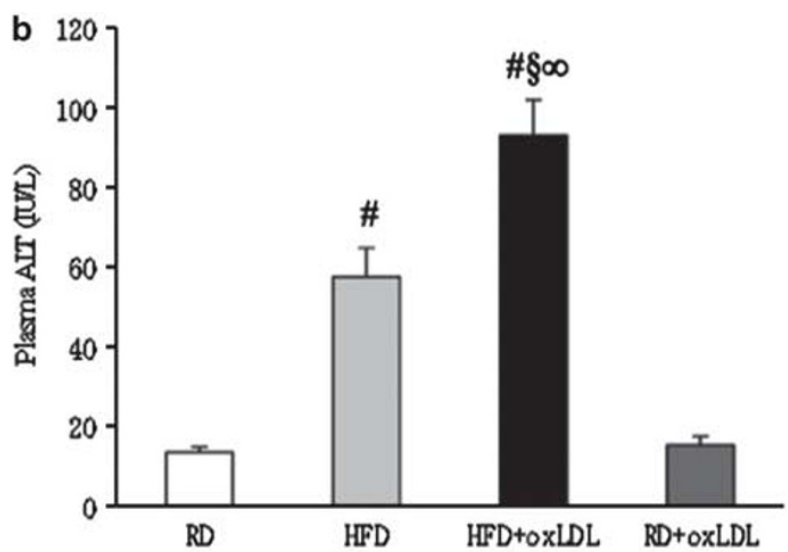

。
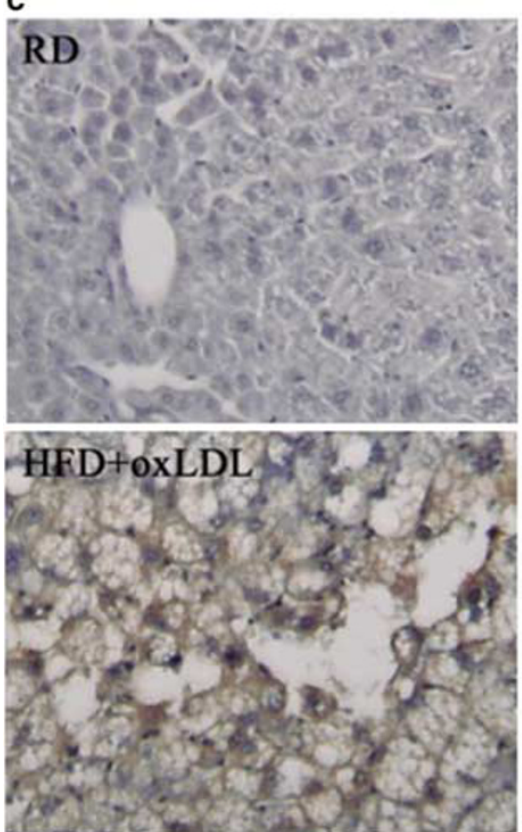
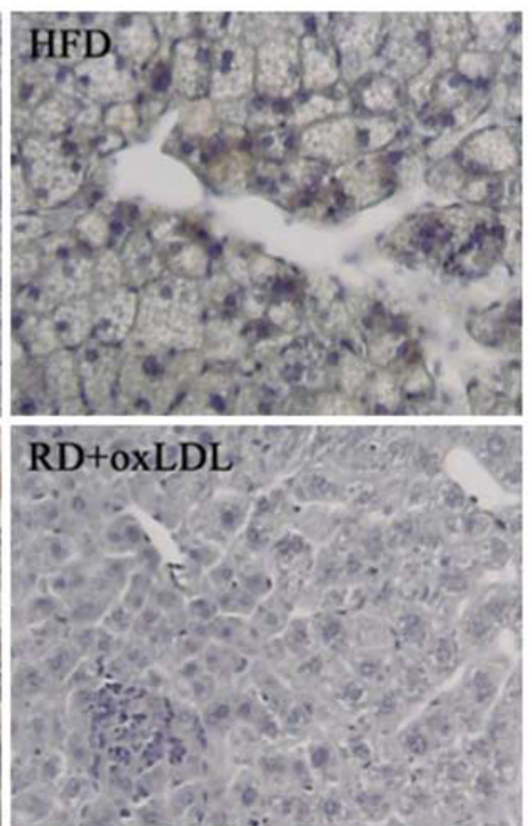

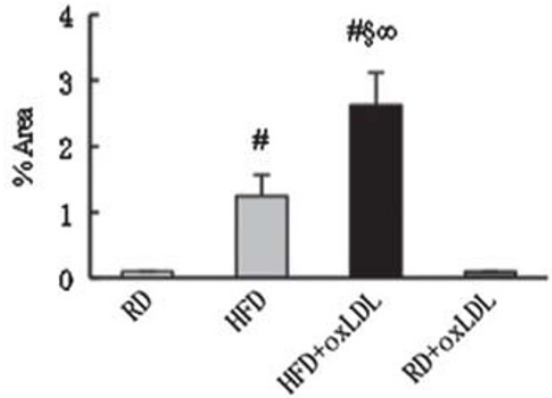

Figure 1 Hepatic morphology and injury in RD-fed, HFD-fed, HFD + oxLDL, and RD + oxLDL mice after 23 weeks of experimental treatment. (a) Representative photographs of livers from each group are shown (scale bars, $10 \mathrm{~mm}$ ). (b) Plasma ALT levels at the end of the experiment are plotted. Data represent the mean \pm s.d. for five mice per treatment group. (c) Representative images (original magnification, $\times 200$ ) of immunohistochemical staining for apoptosis in the liver of each group. Absolute percentages of the field areas are shown. Data are expressed as the mean \pm s.d. of 5-7 mice per treatment group. ${ }^{\#} P<0.001$ versus RD-fed mice; ${ }^{{ }^{P}} P<0.001$ versus HFD-fed mice; ${ }^{\infty} P<0.001$ versus $\mathrm{RD}+$ oxLDL mice.

significant difference in body weight, liver weight, plasma ALT levels, and apoptosis between RD + oxLDL and control mice (Figures $1 \mathrm{~b}$ and $\mathrm{c}$, and Table 3).

\section{Effects of HFD, oxLDL, and Combination on Liver Histopathological Changes in Mice}

Histological images revealed differences in hepatic pathology among the various groups. In contrast to the normal liver histology in RD-fed mice, ballooned hepatocytes, a necessary histological feature defining human $\mathrm{NASH}$, and microvesicular steatosis were observed in HFD-fed mice, along with slight intra-parenchymal fibrosis after 23 weeks (Figures $2 \mathrm{a}$ and $\mathrm{b}$ ). In parallel, oil-red $\mathrm{O}$ staining showed intracytoplasmic lipid accumulation in liver sections from HFD-fed mice (Figure 2c). However, little inflammatory cell infiltration appeared in these mice (Figure 2a). Moreover, administration of oxLDL to HFD-fed mice exacerbated hepatic steatosis and resulted in a considerable number of macrovesicular fat droplets (Figures $2 \mathrm{a}$ and c). In addition to steatosis, an intense inflammatory response, including inflammatory cell infiltration and hepatocellular damage with nuclear vacuolation, and intra-parenchymal pericellular fibrosis were observed in the hepatic lobules of HFD + oxLDL mice, which are typical histological features of NASH (Figures $2 a$ and $b$ ). We also investigated the effect of oxLDL alone on liver histomorphological changes. OxLDL 
Table 3 Body and liver weights, cumulative food and calorie intake, and hepatic and blood levels of biochemical markers in each mouse group

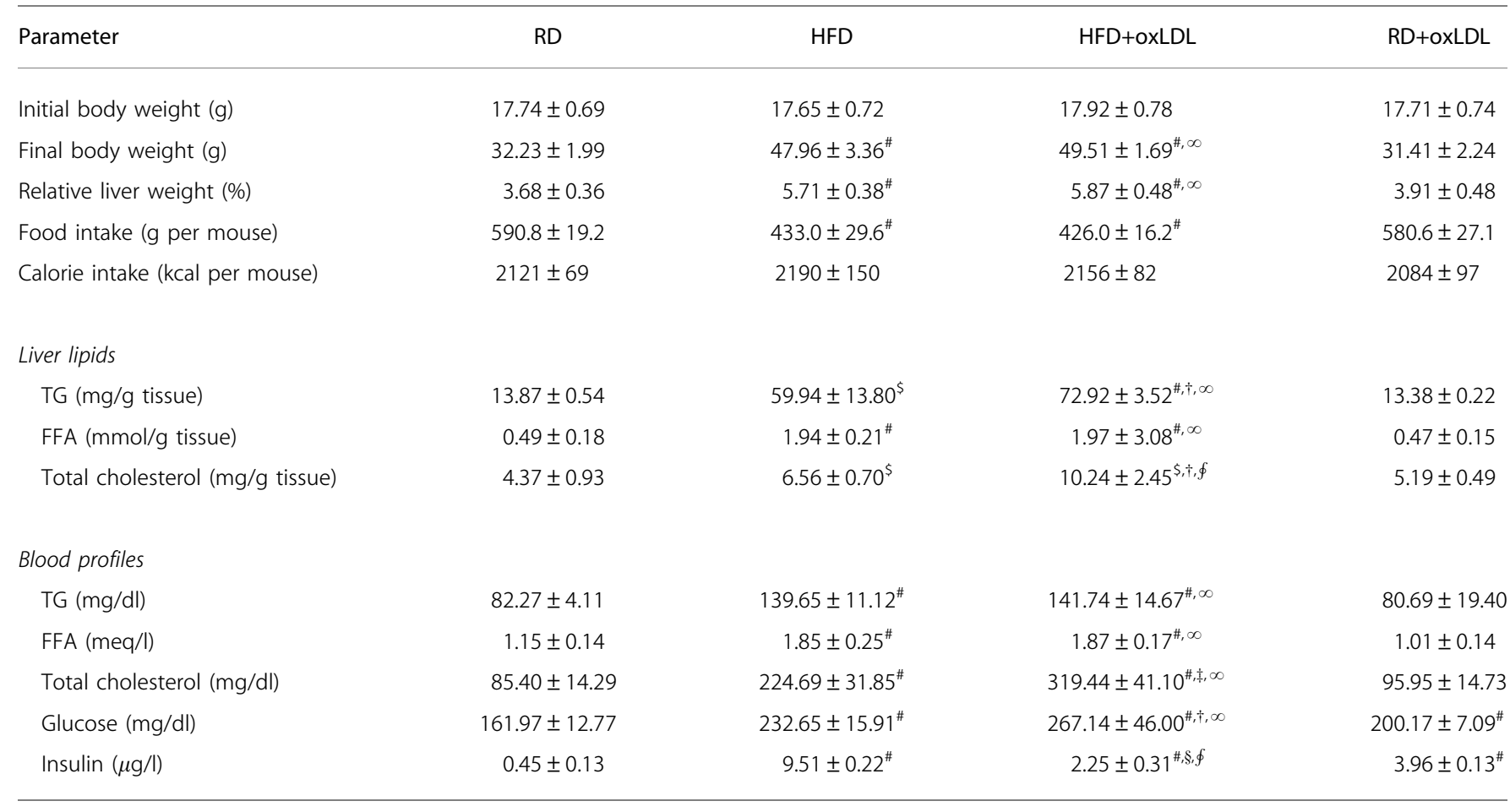

Changes in body and liver weights, cumulative food and calorie intake, and biochemical marker levels in the livers and blood of RD-fed, HFD-fed, HFD+oxLDL, and $\mathrm{RD}+\mathrm{oxLDL}$ murine groups after 23 weeks of experimental treatment. The data represent the means \pm s.d. of 5-7 mice per treatment group.

${ }^{\$} P<0.01,{ }^{\#} P<0.001$ versus RD-fed mice.

${ }^{\dagger} P<0.05,{ }^{\ddagger} P<0.01,{ }^{\S} P<0.001$ versus HFD-fed mice.

${ }^{\oint} P<0.01,{ }^{\infty} P<0.001$ versus RD+oxLDL mice.

administration induced an increase in the number of inflammatory cells in the hepatic parenchyma of RD-fed mice in a time-dependent manner, and recruitment of inflammatory cells and a great many lipid-laden foamy macrophages were clearly observed after 3 weeks (Figures $2 \mathrm{a}$ and c). These mice also developed ballooning degeneration of perivenular hepatocytes but failed to show any liver fibrosis (Figures $2 a$ and $b$ ). The degree of NAFLD in each group after 23 weeks of experimental treatment was quantified and is shown in Table 4.

\section{Effects of HFD, oxLDL, and Combination on Lipid Metabolites and Insulin Responsiveness in Mice}

As lipid accumulation in hepatocytes is a characteristic feature of NASH, we measured hepatic TG, FFA, and cholesterol contents to further evaluate the development of steatosis quantitatively in each mouse group after 23 weeks of experimental treatment. Hepatic biochemical analysis indicated that feeding mice an HFD induced increases in hepatic TG, FFA, and cholesterol levels in comparison with control RDfed mice, which showed negligible fat content (4.32-fold for TG and 1.50-fold for cholesterol $(P<0.01) ; 3.96$-fold for FFA $(P<0.001))$ (Table 3). Although administration of oxLDL to
RD-fed mice during weeks 21-23 failed to change hepatic TG, FFA, and cholesterol levels, these levels were strongly elevated in HFD + oxLDL mice as compared with control RD-fed mice (5.25-fold for TG and 4.02-fold for FFA $(P<0.001)$; 2.34-fold for cholesterol $(P<0.01))$ (Table 3). These data coincided with hepatic histomorphological findings (Figures $2 \mathrm{a}$ and $\mathrm{c}$ ).

Hepatic lipid accumulation was accompanied by dyslipidemia in HFD-fed and HFD + oxLDL mice. As shown in Table 3, compared with the RD-fed group, plasma TG, FFA, and cholesterol levels were significantly elevated in the HFDfed and HFD + oxLDL groups but not in the RD + oxLDL group after 23 weeks of experimental treatment (1.70- and 1.72-fold for TG; 1.61- and 1.63-fold for FFA; and 2.63- and 3.74 -fold for cholesterol, respectively; $P<0.001$ ). Furthermore, higher levels of plasma glucose and insulin were detected in HFD-fed mice than in RD-fed mice (1.44-fold for glucose and 21.13-fold for insulin, respectively; $P<0.001$ ) (Table 3), indicating that HFD induced insulin resistance. Although HFD + oxLDL and RD + oxLDL mice also showed hyperglycemia and hyper-insulinemia (1.65- and 1.24-fold for glucose, and 5.00- and 8.80-fold for insulin versus RD-fed mice, respectively; $P<0.001$ ), the increased insulin level was 

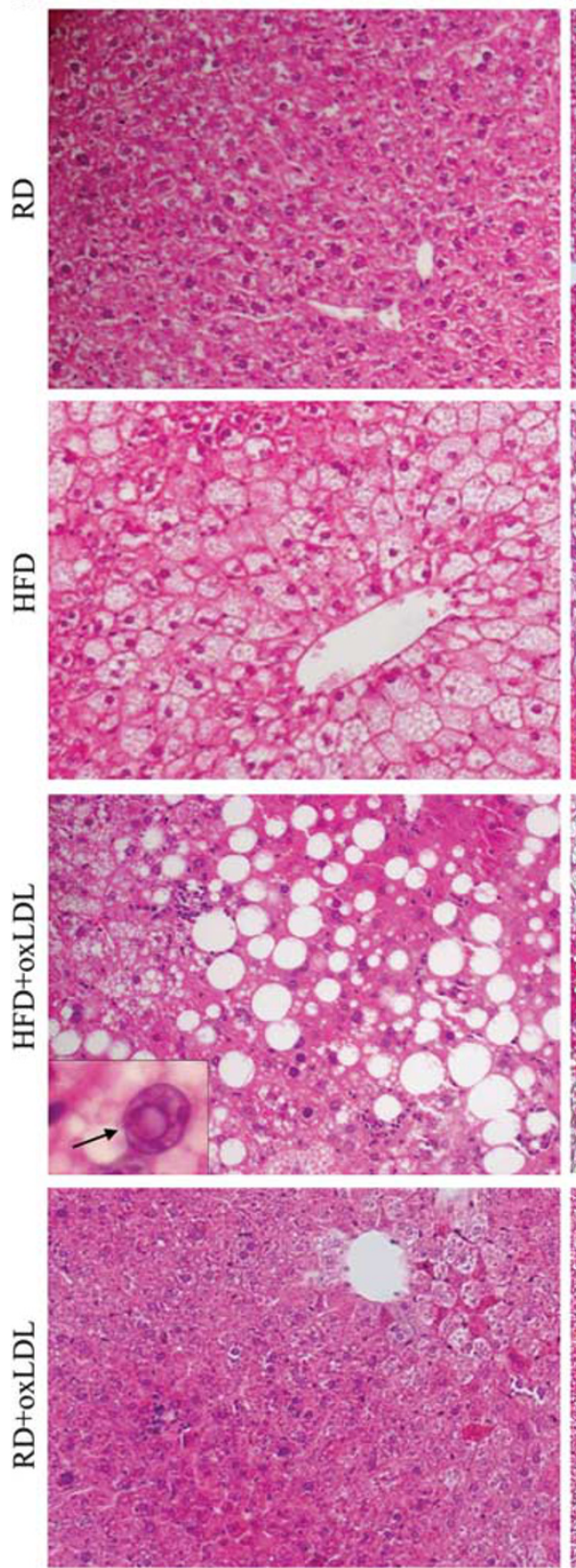

b
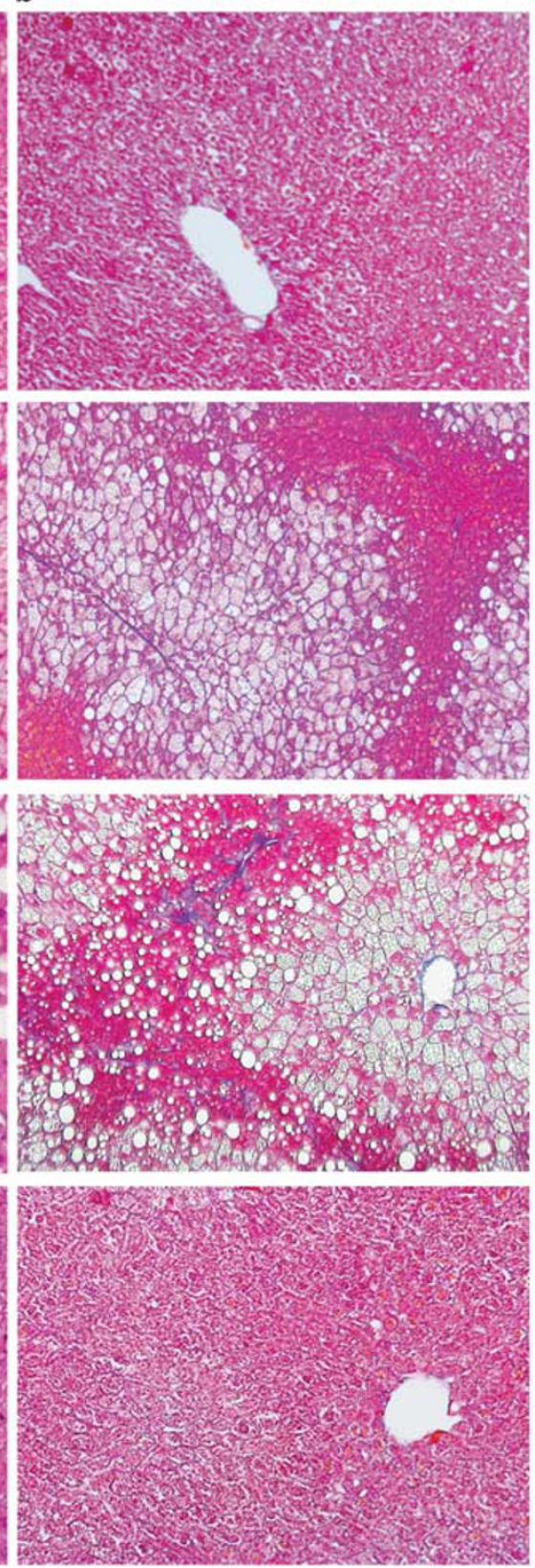

C
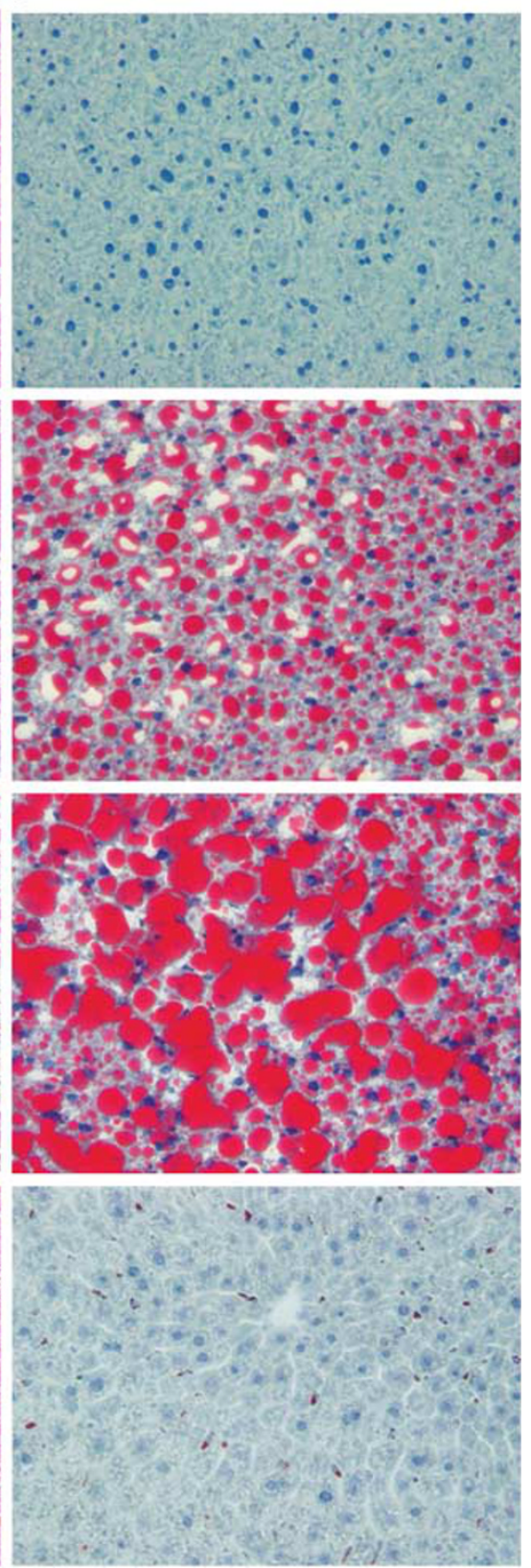

Figure 2 Representative photomicrographs from each mouse group after 23 weeks of experimental treatment. (a) H\&E-stained liver sections (original magnification, $\times 200$ ). Nuclear vacuolation in hepatocytes is shown in the inset. (b) Azan-stained liver sections. Fiber deposition is identified by blue staining (original magnification, $\times 100$ ). (c) Oil-red O-stained liver sections. Hepatic lipid accumulation was determined by oil red $\mathrm{O}$ staining (original magnification, $\times 200)$.

markedly lower in both groups than that in the HFD-fed group (Table $3, P<0.001$ ), suggesting that oxLDL not only induced insulin resistance but also downregulated insulin secretion.

\section{Effects of HFD, oxLDL, and Combination on Hepatic Oxidative Stress in Mice}

We measured the hepatic malondialdehyde level in each group as an index of lipid peroxidation and found that HFD and oxLDL augmented hepatic lipid peroxidation. Mice treated with either HFD for 23 weeks or oxLDL for 3 weeks showed higher levels of malondialdehyde in their livers than control RD-fed mice (1.33-fold, $P<0.01 ; \quad 1.54$-fold, $P<0.001$, respectively) (Figure 3a). Furthermore, a 1.90-fold increase in hepatic lipid peroxidation was noted in HFD + oxLDL mice as compared with RD-fed mice (Figure $3 \mathrm{a}, P<0.001)$. As the endoplasmic reticulum $\omega$-oxidation cytochrome P450-2E1 (CYP2E1) has a key role in the 
Table 4 Hepatic pathology scores in each mouse group

\begin{tabular}{|c|c|c|c|c|c|}
\hline \multirow[t]{2}{*}{ Mice } & \multicolumn{4}{|c|}{ Item } & \multirow[t]{2}{*}{ Total score } \\
\hline & Steatosis & Hepatocellular ballooning & Inflammation & Fibrosis & \\
\hline $\mathrm{RD}(n=5)$ & $0.0 \pm 0.0$ & $0.0 \pm 0.0$ & $0.0 \pm 0.0$ & $0.0 \pm 0.0$ & $0.0 \pm 0.0$ \\
\hline $\operatorname{HFD}(n=6)$ & $1.3 \pm 0.5^{\#}$ & $2.0 \pm 0.0^{\#}$ & $0.0 \pm 0.0$ & $0.8 \pm 0.4^{\#}$ & $4.2 \pm 0.8^{\#}$ \\
\hline HFD+oxLDL $(n=7)$ & $1.9 \pm 0.4^{\#, \dagger, \infty}$ & $2.0 \pm 0.0^{\#, \infty}$ & $2.3 \pm 0.5^{\#, \$, \Phi}$ & $1.3 \pm 0.5^{\#, \dagger, \infty}$ & $7.4 \pm 0.5^{\#, \S, \infty}$ \\
\hline
\end{tabular}

Pathological hepatic NAFLD scores in each mouse group after 23 weeks of experiment. The absolute percentage of the fat droplet area in oil-red O-stained sections was determined to evaluate steatosis. The extension of balloon hepatocytes and the number of inflammatory foci were identified using H\&E-stained sections. Azan-stained sections were used for evaluation of fibrosis. The criteria for each score are described under Materials and Methods. Results are expressed as the mean \pm s.d. of 5-7 mice per treatment group.

${ }^{\#} P<0.001$ versus $\mathrm{RD}$-fed mice.

${ }^{\dagger} P<0.05,{ }^{{ }^{\dagger}} P<0.001$ versus HFD-fed mice.

${ }^{\oint} P<0.01,{ }^{\infty} P<0.001$ versus $\mathrm{RD}+0 \times \mathrm{LDL}$ mice.

initiation of hepatic lipid peroxidation, ${ }^{28}$ we next evaluated its gene expression in the livers of mouse from each group. Real-time PCR analysis revealed a significant increase in CYP2E1 mRNA levels in the livers of HFD-fed and $\mathrm{RD}+$ oxLDL mice (1.34- and 1.26-fold versus RD-fed mice; $P<0.01$ and $P<0.05$, respectively), and a more pronounced upregulation in HFD + oxLDL mice (1.87-fold versus RD-fed mice, $P<0.001$ ) (Figure $3 \mathrm{~b}$ ). The results of immunohistochemical analysis for 8-OHdG are shown in Figure 3c. 8-OHdG-positive cells significantly appeared throughout the lobule of HFD-fed and HFD + oxLDL mice, especially in the latter, whereas in $\mathrm{RD}+$ oxLDL mice they were mainly localized around the hepatic venulae.

\section{Effects of HFD, oxLDL, and Combination on Induction of the Hepatic Inflammatory Response in Mice}

We investigated the contributions of HFD and oxLDL to the hepatic inflammatory response in mice by analyzing the gene expression of tumor necrosis factor (TNF)- $\alpha$ and interleukin (IL)-6, two major inflammatory mediators of macrophages that correlate with progression of NASH. ${ }^{29}$ HFD feeding for 23 weeks resulted in an upregulated hepatic mRNA expression of TNF- $\alpha(1.72$-fold versus RD-fed mice; $P<0.01)$ (Figure 4a). Moreover, a pronounced increase in the hepatic level of the TNF- $\alpha$ gene was found in HFD + oxLDL mice at the end of 23 weeks (5.65-fold versus RD-fed mice and 3.28fold $v$ HFD-fed mice; $P<0.05$ ), but a similar change was not observed in RD + oxLDL mice (Figure 4a). These results also coincided with the degree of liver injury shown in Figures $1 \mathrm{~b}$ and $c$, suggesting that TNF- $\alpha$ mediates hepatocellular injury. Although little inflammatory cell infiltration was observed in the liver of HFD-fed mice, oxLDL administration in these mice resulted in mixed inflammatory infiltration, with macrophages and lymphocytes throughout the hepatic lobule (Figures $4 \mathrm{e}$ and $\mathrm{f}$ ). Additionally, a mild increase in the number of inflammatory cells was observed in the liver of
$\mathrm{RD}+$ oxLDL mice (Figures 4e and f). Real-time PCR analysis also supported the immunohistochemical results (Figures $4 \mathrm{c}$ and d). Consistent with the recruitment of inflammatory cells, hepatic expression of the IL-6 gene was upregulated in HFD + oxLDL and RD + oxLDL groups as compared with expression in the RD-fed group (2.04-fold for HFD + oxLDL mice $(P<0.01)$ and 1.50 -fold for $\mathrm{RD}+$ oxLDL mice $(P<0.05)$, respectively) (Figure $4 \mathrm{~b})$. However, IL-6 mRNA expression was unaltered in the liver of the HFD-fed group (Figure 4b). These data suggest that oxLDL-induced inflammatory cell infiltration is mediated by IL-6.

Furthermore, compared with RD-fed mice, RD-fed mice treated with LDL for 3 weeks did not show any changes in the hepatic histological architecture and gene expression of inflammatory mediators (Figures $4 \mathrm{a}-\mathrm{d}$ and $\mathrm{g}$ ), indicating that the human LDL injection does not induce inflammatory reaction in mice, concordant with the report in which oxLDL, but not native LDL, was shown to contribute to the inflammation of the atherosclerotic regions. ${ }^{30}$

\section{Effects of HFD, oxLDL, and Combination on Hepatic Fibrogenesis in Mice}

Hepatic fibrosis is viewed as one of the advanced consequences of NASH. To clarify the effects of HFD and oxLDL on hepatic fibrosis, the mRNA levels of transforming growth factor (TGF)- $\beta 1$, an important fibrogenetic cytokine, and its target gene, collagen- $\alpha 1$, were compared in the four mouse groups by quantitative real-time PCR after 23 weeks of experimental conditions. Hepatic mRNA expression for TGF$\beta 1$ and collagen- $\alpha 1$ increased 1.73- and 3.06-fold, respectively, in HFD-fed mice as compared with RD-fed mice $(P<0.05$ and $P<0.01$, respectively) (Figures $5 \mathrm{a}$ and $\mathrm{b})$. The combination of HFD and oxLDL induced further upregulation of the hepatic mRNA levels of both genes in mice, particularly collagen- $\alpha 1$ (2.43-fold for TGF- $\beta 1$ and 7.25-fold for collagen- $\alpha 1$ versus RD-fed mice; $P<0.01$ and $P<0.001$, 
a

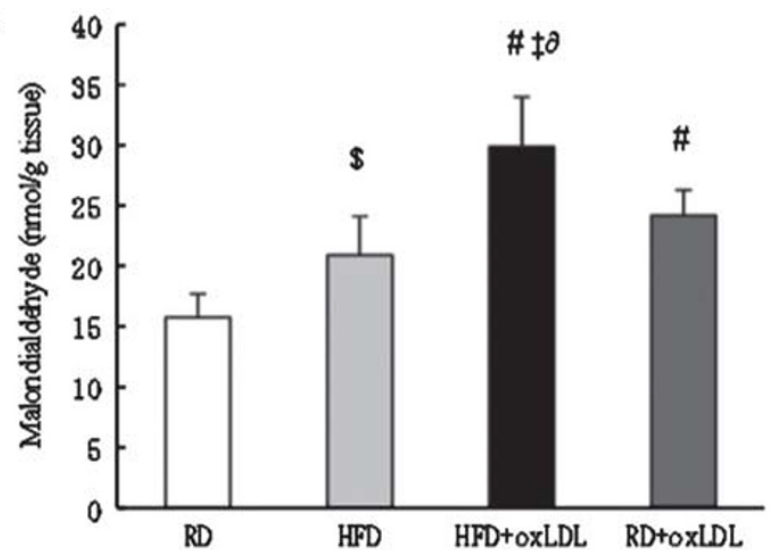

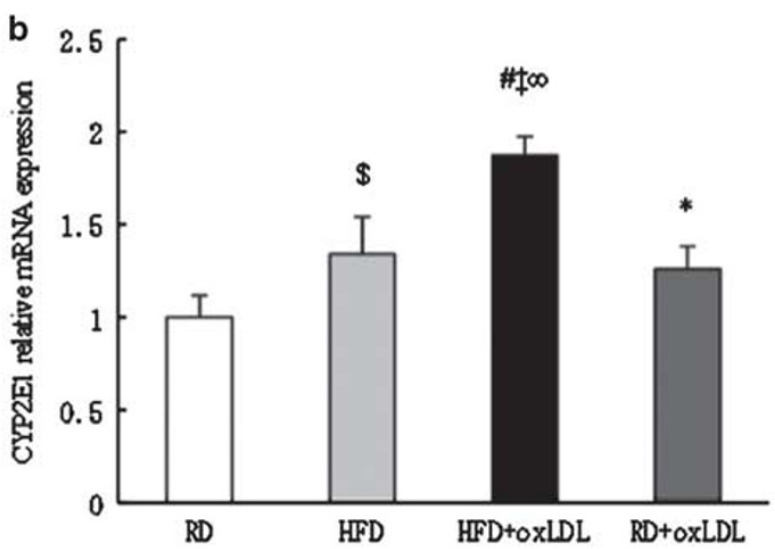

C
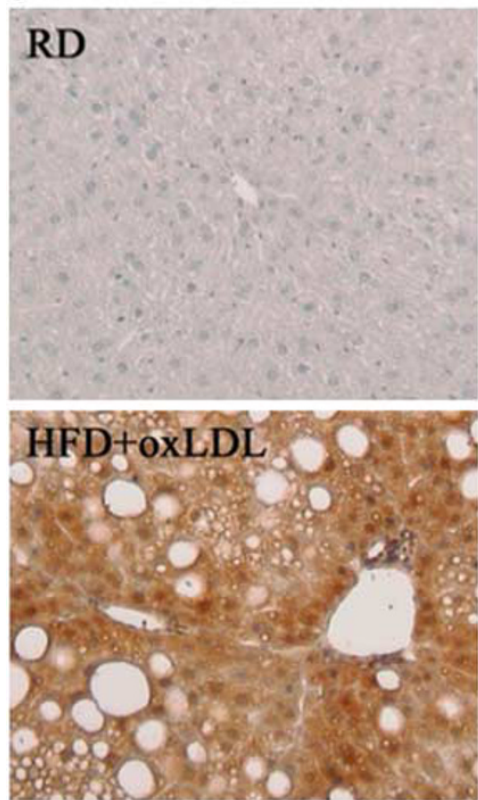
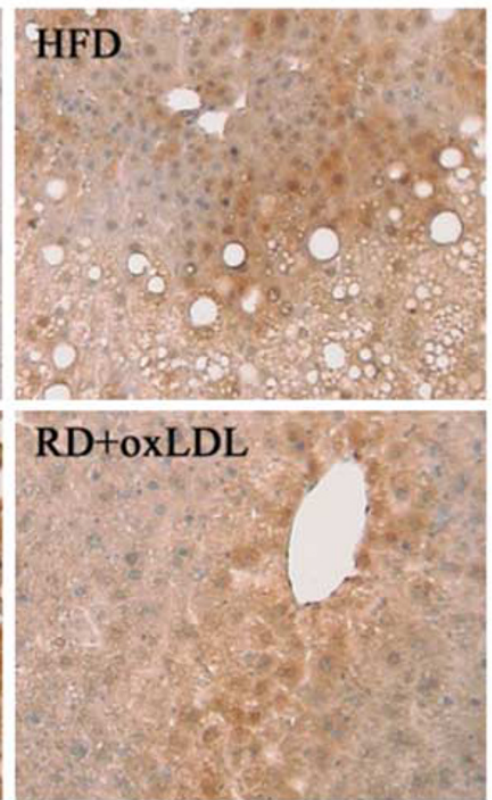

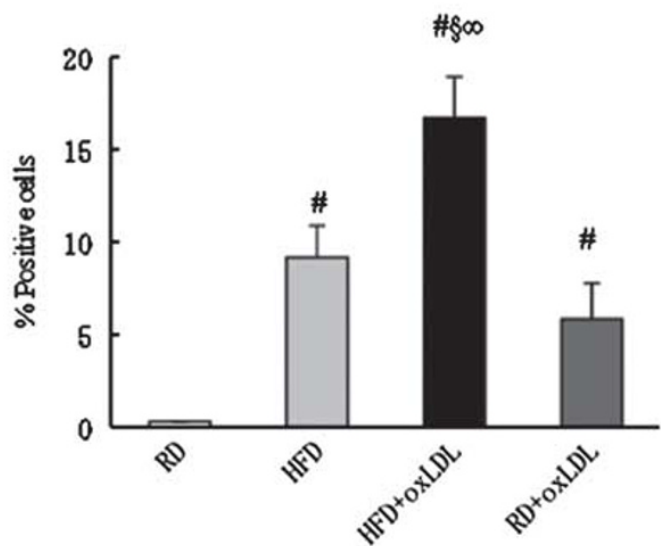

Figure 3 Parameters of hepatic oxidative stress in each murine group after 23 weeks of experimental treatment. Hepatic lipid peroxide levels (a) and relative gene expression of CYP2E1 (b) were measured with a commercial kit and by quantitative real-time PCR, respectively. Data are presented as the mean \pm s.d. for five mice per treatment group. (c) Representative images (original magnification, $\times 200$ ) of immunohistochemistry for 8 -OHdG in the liver of each group and the percentage of positively stained cells are shown. Nuclei stained brown showed positive immunoreactivity toward the monoclonal primary antibody against 8-OHdG. Data are expressed as the mean \pm s.d. of 5-7 mice per treatment group. ${ }^{\star} P<0.05,{ }^{\$} P<0.01,{ }^{\#} P<0.001$ versus RD-fed mice; ${ }^{\ddagger} P<0.01,{ }^{\S} P<0.001$ versus HFD-fed mice; ${ }^{\partial} P<0.05,{ }^{\infty} P<0.001$ versus $\mathrm{RD}+$ oxLDL mice.

respectively) (Figures $5 \mathrm{a}$ and $\mathrm{b}$ ). However, no change in the gene levels of TGF- $\beta 1$ and collagen- $\alpha 1$ were observed in $\mathrm{RD}+\mathrm{oxLDL}$ mice (Figures $5 \mathrm{a}$ and $\mathrm{b}$ ). To further assess the effects of HFD and oxLDL on hepatic fibrosis, immunohistochemical analysis of collagen type-1 was performed. As predicted from the results of its gene expression, HFD-fed mice showed mild collagen type-1 expression in the liver; a more pronounced intra-parenchymal expression of collagen type-1 was observed in HFD + oxLDL mice; and no collagen expression was observed in the livers of RD + oxLDL mice (Figure 5c). These data were consistent with the development of hepatic fibrosis in each group of mice, as shown in Figure $2 b$.
Effects of HFD, oxLDL, and Combination on PPAR- $\gamma$ and CD36 Expression in Mice

We also compared the levels of peroxisome proliferatoractivated receptor (RRAR)- $\gamma$, a major factor in lipid uptake, and its target gene, CD36, among the four groups of mice at the end of the experimental period. In comparison with control RD-fed mice, the hepatic mRNA levels of PPAR- $\gamma$ and CD36 were both markedly elevated in the HFD-fed group (2.58- and 2.98-fold, respectively; $P<0.001$ ) and the HFD + oxLDL group (3.99- and 4.28-fold, respectively; $P<0.01$ ) (Figures $6 \mathrm{a}$ and $\mathrm{b}$ ). The latter manifested more significant increases than the former (Figures $6 a$ and $b$, $P<0.05)$. However, there were no changes in the expression 
a

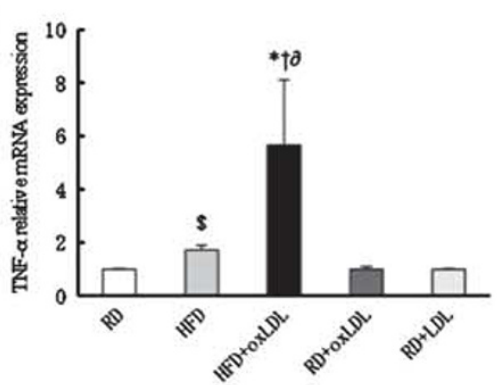

C

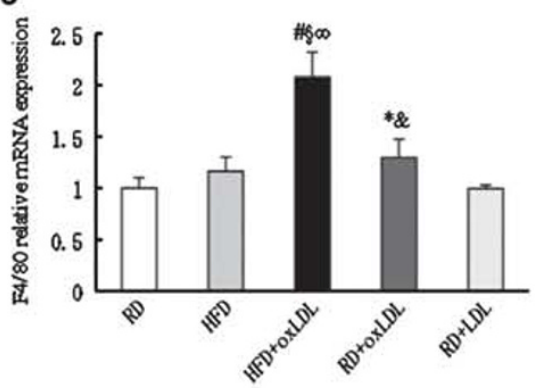

e

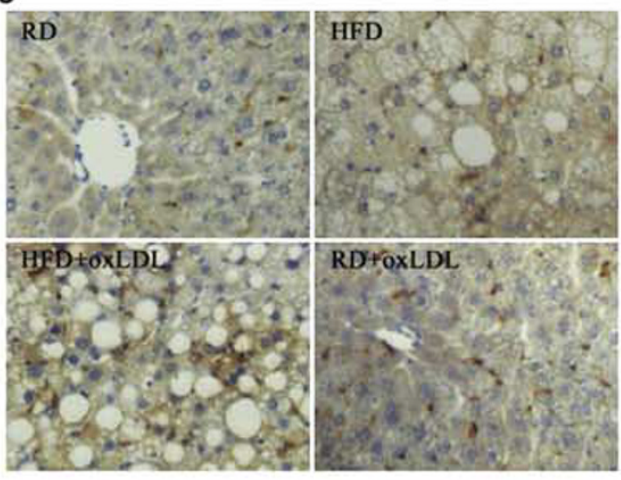

f

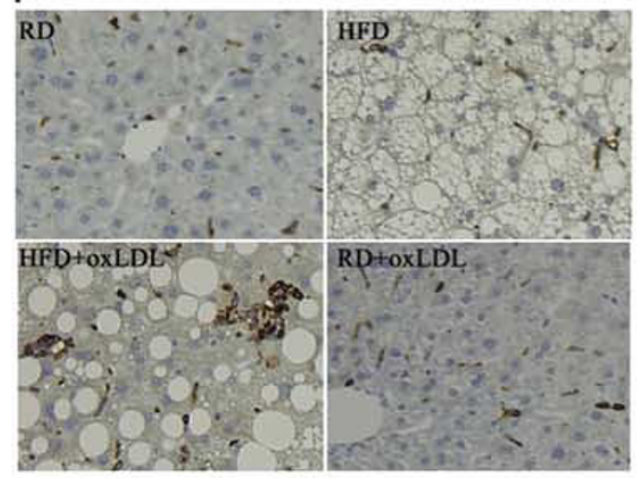

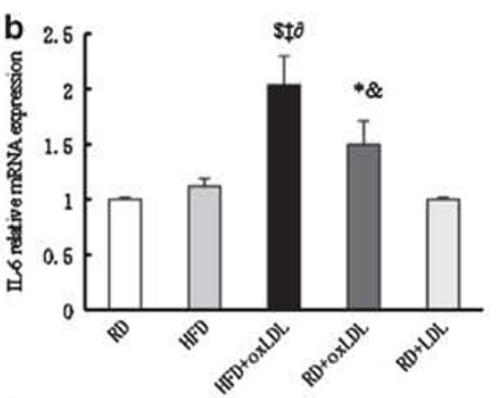

d

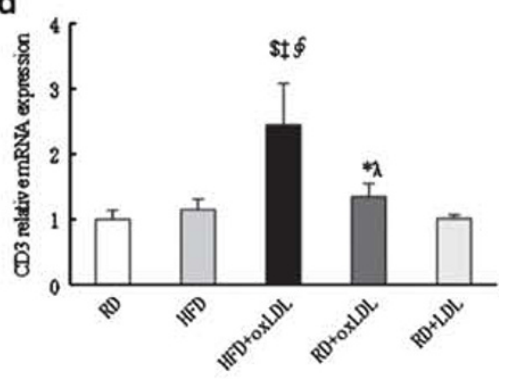

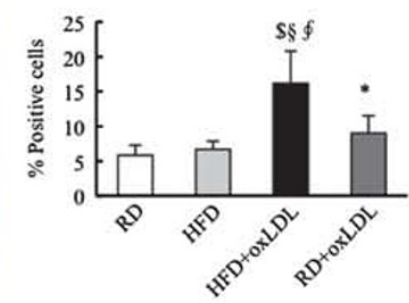

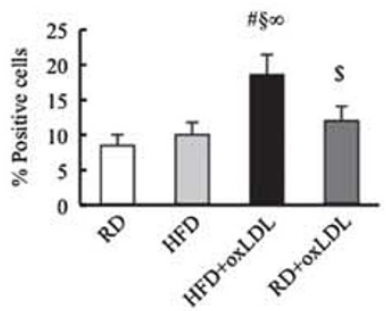

g

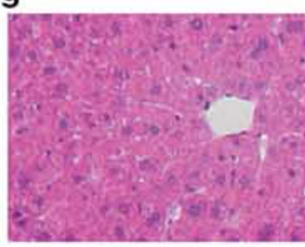

H\&E

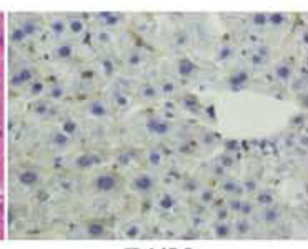

F4/80

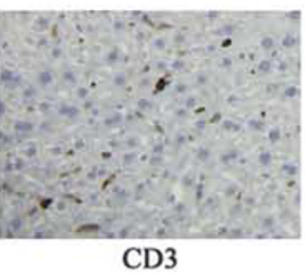

CD3 
of both genes in the livers of the RD + oxLDL group (Figures $6 \mathrm{a}$ and $\mathrm{b}$ ). We further examined CD36 protein expression in the liver tissues of each group after 23 weeks. It has been reported that CD36 expression is normally low in rodent liver. ${ }^{31}$ However, our immunohistochemistry data showed that long-term HFD feeding resulted in upregulated hepatocellular CD36 expression in mice (Figure 6c). Moreover, oxLDL showed a synergistic effect in terms of a

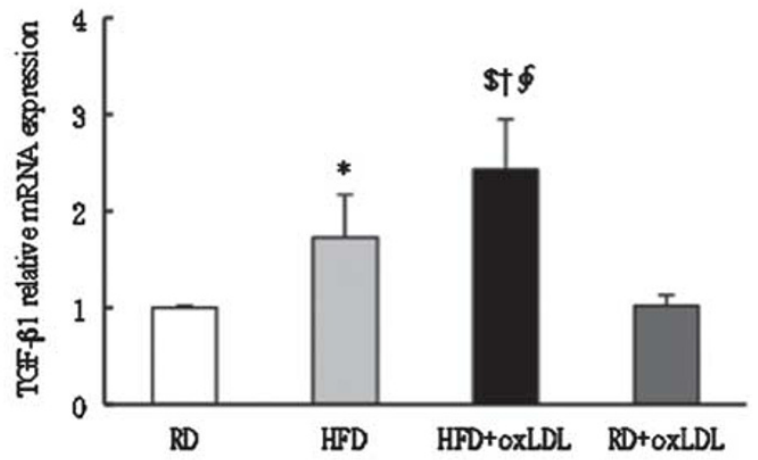

b

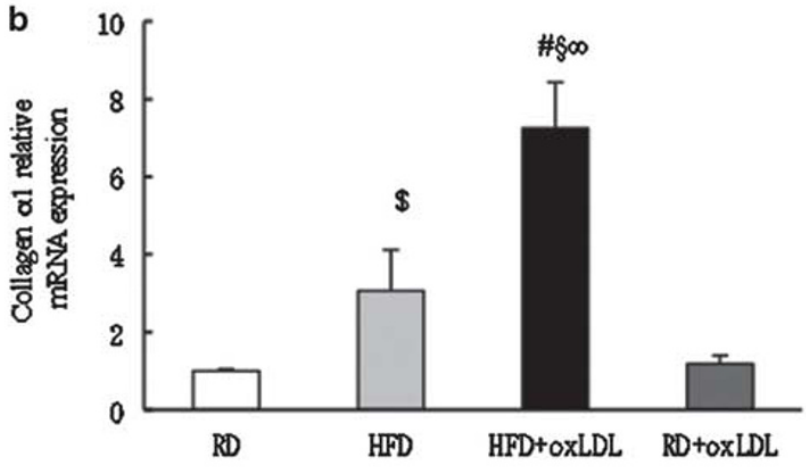

C
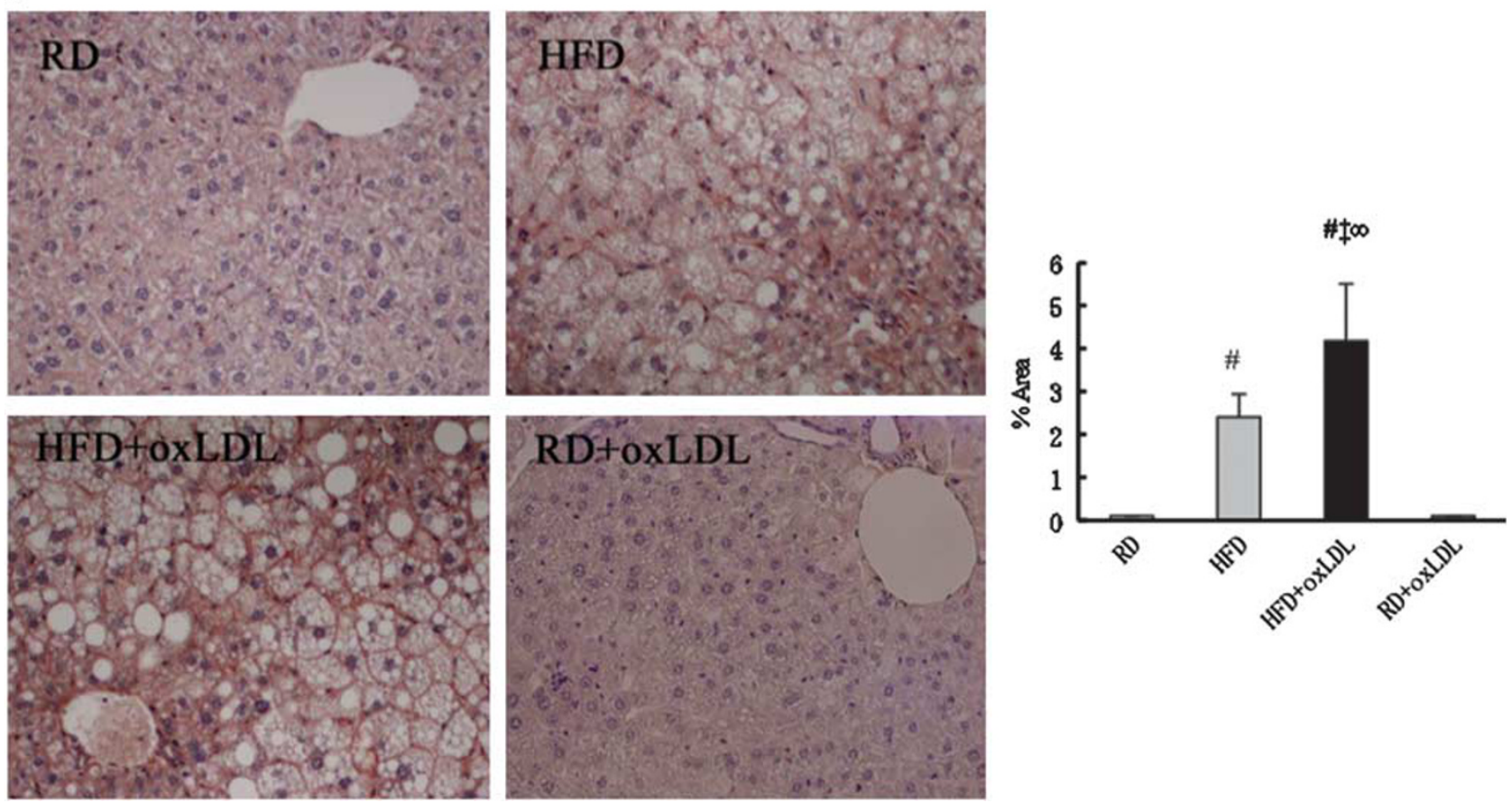

Figure 5 Fibrosis markers in liver tissues from each mouse group after 23 weeks of experimental treatment. Quantitative analysis showed the ratio of the mRNA expression for TGF- $\beta 1$ (a) and collagen- $\alpha 1$ (b) normalized to the GAPDH gene. Data are expressed as mean \pm s.d. for five mice. (c) Representative photomicrographs (original magnification, $\times 200$ ) of liver sections stained with an anti-collagen type- 1 antibody and the percentage of collagen type-1 expression are shown. Brown staining indicates positive immunohistochemistry for collagen type-1 protein expression. Data are expressed as the mean \pm s.d. of $5-7$ mice per treatment group. ${ }^{\star} P<0.05,{ }^{\$} P<0.01,{ }^{\sharp} P<0.001$ versus RD-fed mice; ${ }^{\dagger} P<0.05,{ }^{\ddagger} P<0.01,{ }^{\$} P<0.001$ versus HFD-fed mice; ${ }^{\S_{P}}<0.01,{ }^{\infty} P<0.001$ versus $\mathrm{RD}+\mathrm{oxLDL}$ mice.

Figure 4 Parameters of hepatic inflammation in each murine group after 23 weeks of experimental treatment. The gene expression levels of TNF- $\alpha$ (a), IL-6 (b), F4/80 (c), and CD3 (d) were determined by quantitative real-time PCR analysis of total RNA from mouse liver tissues. Results were normalized to the expression of the GAPDH housekeeping gene and are shown as fold changes relative to gene expression in RD-fed mice. Data are presented as the mean \pm s.d. for five mice per treatment group. To identify the infiltrating cell types, murine livers were immunostained for macrophages (F4/80 antibody) and $\mathrm{CD}^{+}{ }^{+}$cells (anti-CD3 ${ }^{+}$antibody). Representative photomicrographs (original magnification, $\times 200$ ) of liver sections stained with an F4/80 antibody (e) and an anti-CD3 ${ }^{+}$antibody (f), and the percentage of positively stained cells are shown. Data are expressed as the mean \pm s.d. of 5-7 mice per treatment group. (g) Liver sections from RD-fed mice treated with LDL were stained with H\&E, an F4/80 antibody, and an anti-CD3 ${ }^{+}$antibody. Representative photomicrographs (original magnification, $\times 200$ ) are shown. Data are expressed as the mean \pm s.d. of three mice. ${ }^{\star} P<0.05$, ${ }^{\$} P<0.01,{ }^{\#} P<0.001$ versus RD-fed mice; ${ }^{\dagger} P<0.05,{ }^{\ddagger} P<0.01,{ }^{\S} P<0.001$ versus HFD-fed mice; ${ }^{\partial} P<0.05,{ }^{\S} P<0.01,{ }^{\infty} P<0.001$ versus RD + oxLDL mice; ${ }^{\lambda} P<0.05,{ }^{\&} P<0.01$ versus RD + LDL mice. 
a

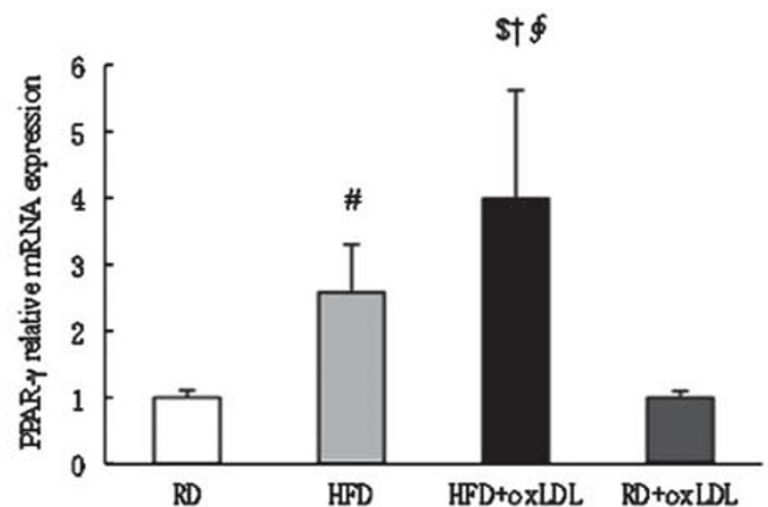

b

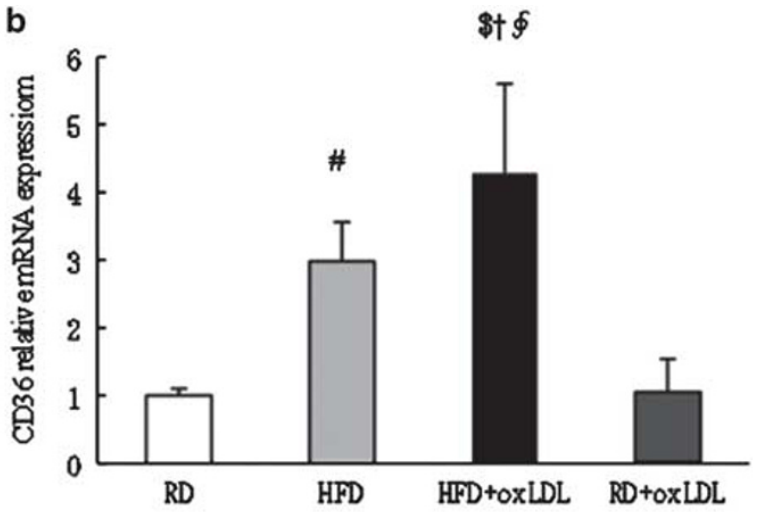

C
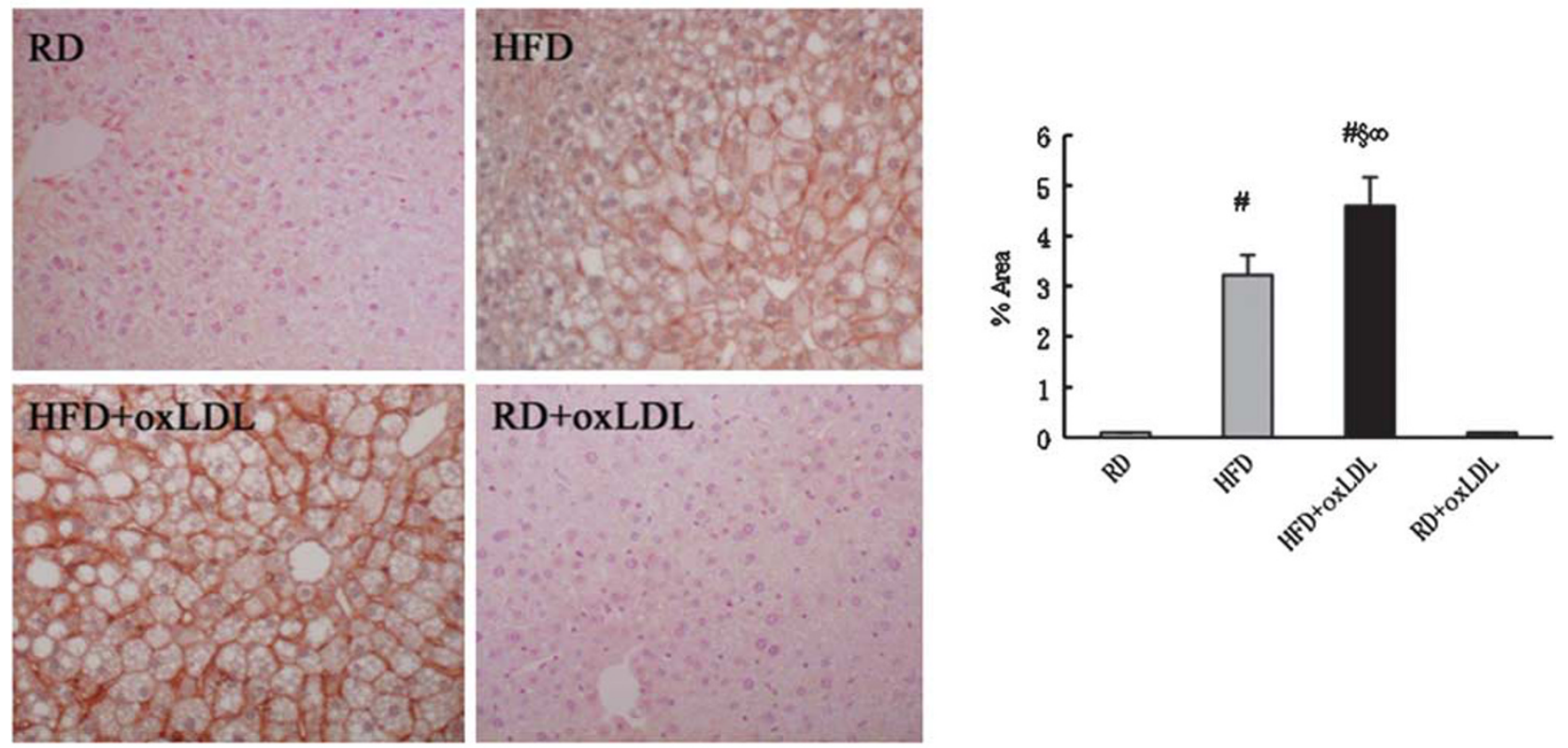

d
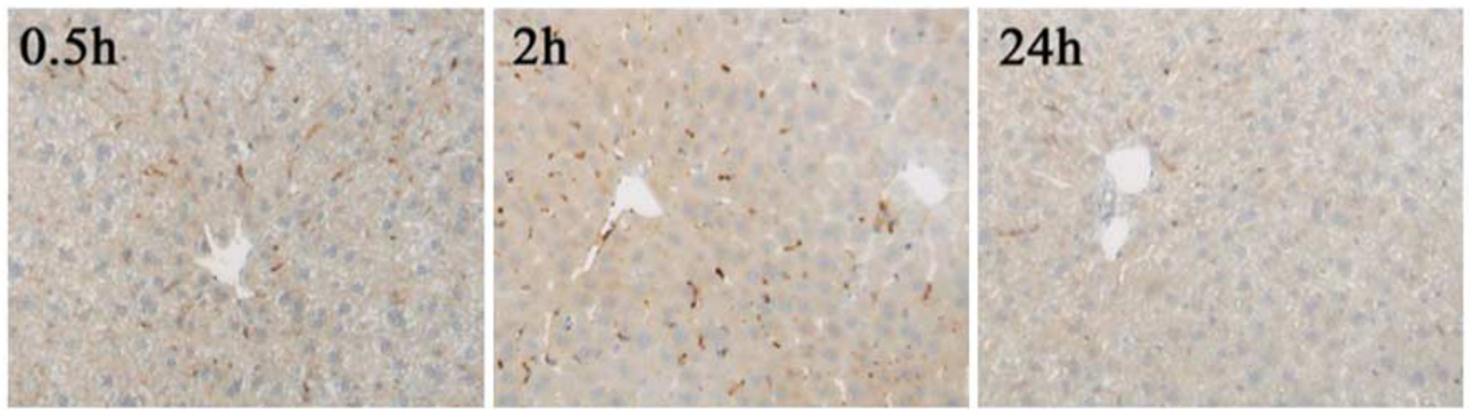

Figure 6 Hepatic expression levels of PPAR $\gamma$ and CD36 in each group of mice. The mRNA expression of PPAR (a) and CD36 (b) was evaluated by quantitative real-time PCR analysis and normalized to the housekeeping gene GAPDH after 23 weeks of experimental treatment. Data are expressed as the mean \pm s.d. of five mice. (c) CD36 protein expression was evaluated by immunohistochemistry in the liver samples from each murine group after 23 weeks of experimental treatment. Representative photomicrographs (original magnification, $\times 200$ ) and the percentage of sections that stained positively for CD36 are shown ( $n=5-7$ mice per treatment group). (d) Immunohistochemical assessment of CD36 expression on hepatic macrophages was performed in RD-fed mice that were treated with oxLDL for different durations. Representative photomicrographs (original magnification, $\times 200)$ are shown $(n=3$ mice per group). ${ }^{\$} P<0.01,{ }^{\#} P<0.001$ vs RD-fed mice; ${ }^{\dagger} P<0.05,{ }^{\$} P<0.001$ versus HFD-fed mice; ${ }^{\S} P<0.01,{ }^{\infty} P<0.001$ versus RD + oxLDL mice.

promotion of $\mathrm{CD} 36$ expression in the livers of the HFD + oxLDL group (Figure 6c). These findings are consistent with changes in CD36 mRNA levels (Figure 6b). However, no hepatic CD36 expression was observed in the
$\mathrm{RD}+\mathrm{oxLDL}$ mice (Figure 6c). Because oxLDL uptake is mainly mediated by the macrophage $\mathrm{CD} 36$ receptor, ${ }^{32,33}$ we further investigated temporal changes in the hepatic expression of CD36 protein in RD-fed mice after oxLDL 
administration. As shown in Figure 6d, CD36 expression on hepatic macrophages of these mice appeared at $0.5 \mathrm{~h}$ after injection, and an increasing number of CD36-positive cells were detected until $2 \mathrm{~h}$. Thereafter, the CD36-positive cells decreased and nearly disappeared at $24 \mathrm{~h}$.

\section{Effects of oxLDL on Foam Cell Formation and CD36 Expression in Macrophages}

As foamy macrophages were observed in the hepatic tissue sections of $\mathrm{RD}+$ oxLDL mice in vivo (Figure $2 \mathrm{c}$ ), we performed in vitro studies using murine peritoneal macrophages from $\mathrm{RD}$-fed mice to investigate the ability of oxLDL to induce foam cell formation and cellular CD36 expression. Upon treatment with oxLDL, accumulation of cytosolic lipids in macrophages and foam cell formation were observed by oil-red $\mathrm{O}$ staining at $24 \mathrm{~h}$ (Figure $7 \mathrm{a}$ ). A significant increase in CD36 gene expression was also detected in the macrophages after $1 \mathrm{~h}$ of stimulation and this increase continued in a time-dependent manner for at least $24 \mathrm{~h}$ (2.09-fold at $1 \mathrm{~h}$ and 2.83 -fold at $24 \mathrm{~h}$ versus untreated macrophages; $P<0.01$ and $P<0.001$, respectively) (Figure $7 \mathrm{~b}$ ). However, confocal microscopic analysis revealed rapid upregulation of the $\mathrm{CD} 36$ protein on the cell surface after $5 \mathrm{~min}$ of stimulation with oxLDL, which peaked between 15 and $60 \mathrm{~min}$, and declined thereafter (Figure 7c). These results are consistent with the in vivo observations shown in Figure 6d.

\section{DISCUSSION}

The two-hit hypothesis for NASH progression suggests that fat deposition in hepatocytes is the first essential step in the progression to NASH. ${ }^{7}$ The current view from experimental studies on the pathogenesis of NASH is also consistent with the importance of steatosis in the development of NASH. ${ }^{11,34}$ Thus, we first established a dietary model for hepatic steatosis by feeding wild-type mice an HFD for 23 weeks (Figures 1a, and $2 \mathrm{a}$ and $\mathrm{c}$; Tables 3 and 4). Biochemical analyses verified alterations in lipid metabolism in these mice (Table 4). However, the molecular details of steatogenesis are not well understood. Several studies have demonstrated that the adipogenesis-related gene, PPAR- $\gamma$, and its target gene, CD36, are responsible for fatty acid uptake and hepatic steatosis, ${ }^{35,36}$ and that CD36-facilitated fatty acid uptake is regulated by membrane lipid rafts and caveolae. ${ }^{31,37}$ Recently, it was reported that abnormal upregulation of $\mathrm{CD} 36$ on the plasma membrane of hepatocytes contributes to hepatic fat accumulation, insulin resistance, and hyper-insulinemia in patients with NAFLD. ${ }^{38,39}$ Consistent with these reports, the hepatic mRNA and protein levels of PPAR- $\gamma$ and CD36 were abnormally elevated, and hyperglycemia and hyperinsulinemia were also observed in HFD-fed mice (Figures $6 \mathrm{a}-\mathrm{c}$ and Table 3), confirming that the PPAR- $\gamma$-signaling pathway and CD36 are involved in HFD-induced NAFLD.

Our data also clearly showed high levels of CYP2E1 mRNA expression and lipid peroxidation products in the livers of
HFD-fed mice (Figures 3a and b). Increasing evidence has shown that CYP2E1 is the central pathway for generation of lipid peroxides, and its mRNA levels are significantly upregulated in response to HFD in mice. ${ }^{28,40}$ Furthermore, lipid peroxidation, as the main second hit of the two-hit hypothesis, contributes to the pathogenic transition from steatosis to NASH by activating hepatic macrophages to trigger inflammation and inducing hepatocyte injury. ${ }^{8,41}$ Therefore, the hepatic injury observed in the HFD-fed mice is considered to be at least partly attributable to elevated oxidative lipids (Figures $1 \mathrm{~b}$ and $\mathrm{c}$, and $3 \mathrm{a}$ ). Although 23 weeks of treatment with HFD failed to increase hepatic recruitment of inflammatory cells in the mice, elevated TNF- $\alpha$ gene expression was detected in their livers, showing a trend toward the Th-1 polarized inflammatory response (Figures 2a, and $4 \mathrm{a}$ and $\mathrm{c}-\mathrm{f}$, and Table 4). TNF- $\alpha$ has been found to not only induce hepatic inflammation and subsequent apoptosis, ${ }^{4}$ but is also associated with insulin resistance. ${ }^{10,42}$ In this study, apoptotic hepatocytes, hyperinsulinemia, and hyperglycemia were detected in HFD-fed mice (Figure 1c and Table 3), further supporting the importance of this cytokine in the associations among lipid peroxidation, inflammation, and insulin sensitivity. We further observed that HFD exposure resulted in upregulated expression levels of TGF- $\beta 1$ and collagen- $\alpha 1$ genes, as well as collagen synthesis, leading to slight hepatic fibrosis in the mice (Figures $2 \mathrm{~b}$ and $5 \mathrm{a}-\mathrm{c}$, and Table 4 ). Other studies have showed that Kupffer cells (hepatic resident macrophages) are activated in diet-induced hepatic steatosis ${ }^{42,43}$ and Kupffer cell-derived TGF- $\beta 1$ initiates collagen production in hepatic stellate cells (HSCs). ${ }^{44}$ It was also reported that lipid peroxidation in hepatocytes mediates the activation of HSCs in a rat model for hepatic fibrosis. ${ }^{45}$ Considering our observations and these previous reports, we conclude that not only hepatic macrophages but also stellate cells are activated during states of over-nutrition.

We administrated oxLDL to HFD-fed mice in order to develop a better experimental model that mimics human $\mathrm{NASH}$, in which inflammatory response, including hepatocellular injury and inflammatory cell infiltration, occurs. OxLDL is regarded as an extracellular source of reactive oxygen species and initiates intracellular oxidative stress in cultured cells. ${ }^{19,20}$ Kupffer cells, the main liver site for oxLDL uptake, reportedly lead to hepatic inflammation through the process of oxLDL uptake. ${ }^{11}$ As expected, HFD + oxLDL animals showed increased accumulation of inflammatory cells and severe hepatocellular injury, as well as high expression levels of both the TNF- $\alpha$ and IL- 6 genes (Figures $1 \mathrm{~b}$ and c, 2a and 4a-f, and Table 4). Additionally, inflammatory infiltration and foamy macrophages were also observed in the livers of $\mathrm{RD}+\mathrm{oxLDL}$ mice, which were accompanied by enhanced gene expression of IL-6 but not TNF- $\alpha$ (Figures 2a and $c$, and $4 \mathrm{a}-\mathrm{f}$, and Table 4). These results indicate that oxLDL contributes to inflammatory response in which TNF- $\alpha$ is implicated in liver injury whereas inflammatory cell 
a

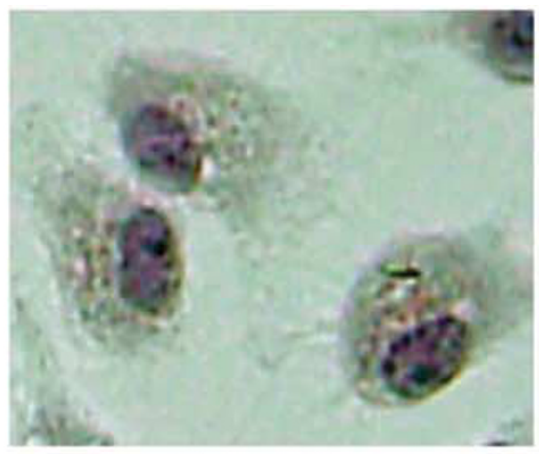

untreated

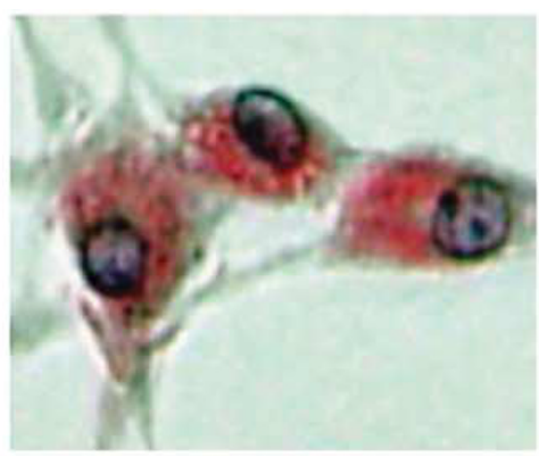

oxLDL-treated

b

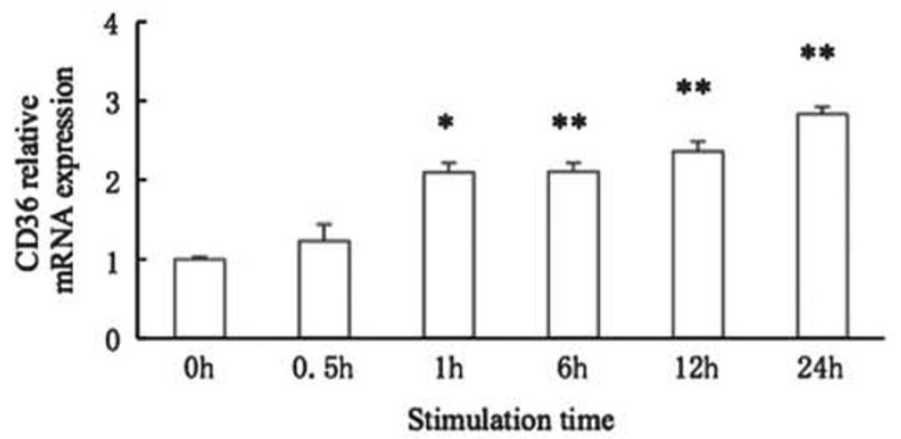

c

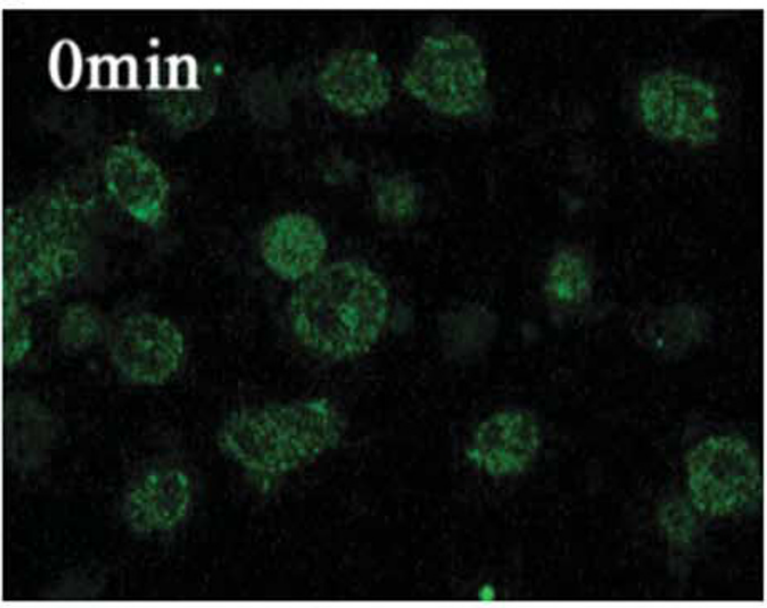

$15 \mathrm{~min}$

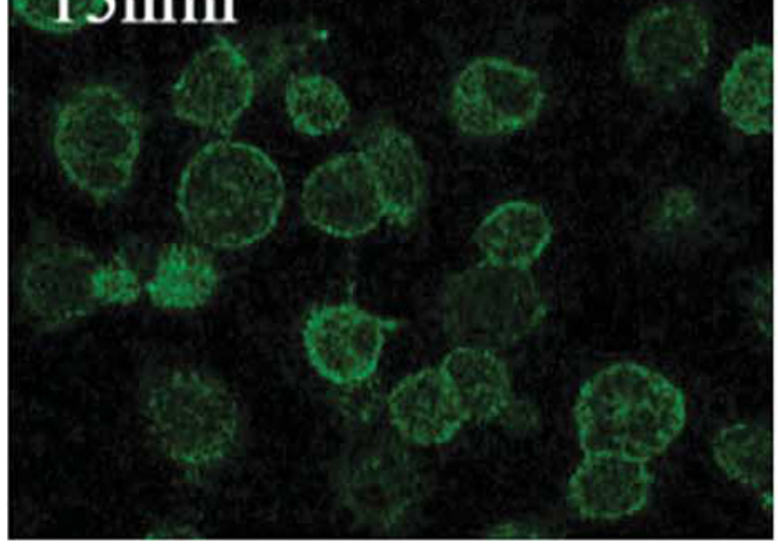

\section{$5 \mathrm{~min}$}

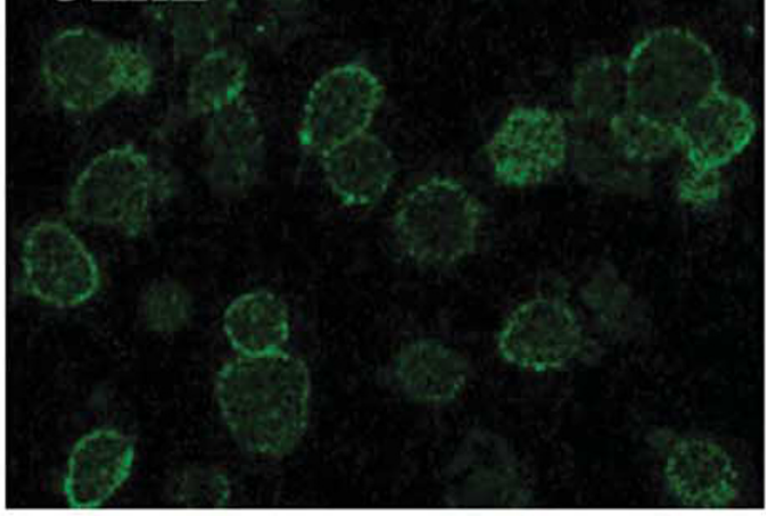

$60 \mathrm{~min}$

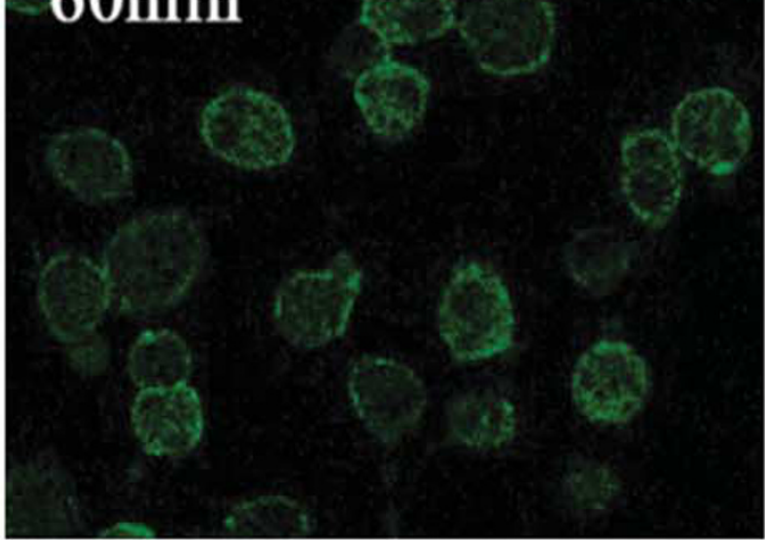


infiltration is mainly mediated by IL-6. IL-6 reportedly induces and accelerates mononuclear cell accumulation in the site of inflammation. ${ }^{4,46}$ Clinical and experimental data demonstrated that expression of the TNF- $\alpha$ and IL- 6 genes is increased in the livers of patients with NASH and its rodent models, and that increased expression of these genes in liver tissues positively correlates with the severity of liver disease..$^{29,47}$ In addition to inflammation, the impact of oxLDL on liver tissue was characterized by exacerbation of steatosis and lipid metabolic abnormality, and the progression to advanced fibrosis in HFD + oxLDL mice as compared with HFD-fed mice (Figures $2 \mathrm{a}-\mathrm{c}$ and $5 \mathrm{a}-\mathrm{c}$, and Tables 3 and 4). Increased steatosis is thought to be associated with hepatic CD36 upregulation seen in HFD + oxLDL mice (Figures $6 \mathrm{~b}$ and $\mathrm{c}$ ). CD36 has also been reported to contribute to insulin resistance and hyper-insulinemia. ${ }^{38,48}$ Interestingly, the increased level of plasma insulin in the HFD + oxLDL group under hyperglycemic condition was significantly lower than that of the HFD-fed group (Table 4). Similar results were also obtained with RD + oxLDL mice (Table 4). These findings suggest that, despite its ability to induce insulin resistance, oxLDL preferentially downregulates insulin secretion in this model. It has been reported that oxLDL reduces preproinsulin mRNA expression and secretion of insulin in islet $\beta$-cells, which are susceptible to oxidative stress. ${ }^{49}$ Our results also indicate that oxLDL has crucial roles in potentiating the entire pathological spectrum of NASH, and these effects are not only due to its own biological properties, but are also mediated by intra-hepatic cytokines, such as IL-6, which may promote hepatocyte steatosis, apoptosis, and insulin resistance, similar to TNF- $\alpha .{ }^{4,20}$ Treatment with oxLDL for 3 weeks also induced cellular ballooning and an increased oxidative state in the livers of RD-fed mice, but did not lead to steatosis, apoptosis, and fibrosis (Figures 1c, 2a-c, $3 \mathrm{a}-\mathrm{c}$ and $5 \mathrm{a}-\mathrm{c}$, and Tables 3 and 4). OxLDL-induced cellular responses were reported to be dependent on the exposure duration and the concentration of oxLDL. ${ }^{50}$ Thus, it is possible that a more longitudinal administration of oxLDL may be essential for accelerating hepatocyte ballooning leading to steatosis and hepatic inflammation. There is also a possibility that a steatosis background makes the liver susceptible to oxLDLinduced injury.

A recent study showed that hepatic steatosis precedes inflammation and inflammation precedes fibrosis in the development of NASH. ${ }^{51}$ By contrast, inflammation as characterized by macrophage inflammation preceded steatosis in a mouse model for NASH. ${ }^{52}$ In the current study, hepatic inflammation and cellular ballooning were prominently developed in $\mathrm{RD}+$ oxLDL mice in which no steatosis was observed (Figures $2 \mathrm{a}-\mathrm{c}$ and $4 \mathrm{a}-\mathrm{f}$, and Table 4 ). These observations suggest that there are a variety of pathologies in the progression to NASH, which might be mediated by different pathophysiological mechanisms. Therefore, appreciating the NAFLD condition will be beneficial for NASH therapies.

Macrophage uptake of oxLDL induced foam cell formation in our study (Figure 7a), which is consistent with other in vitro studies. ${ }^{53-55}$ However, there is presently little in vivo evidence of this. Importantly, bloated foamy macrophages that resembled foam cells in atherosclerosis appeared in the livers of $\mathrm{RD}+$ oxLDL mice but not in the livers of $\mathrm{RD}$-fed mice (Figure 2c). Therefore, this result suggests for the first time that lipids, which generate foam cells in vivo, are largely derived from oxidized lipoproteins. It has been extensively shown that macrophage uptake of oxLDL is mainly mediated by CD36, which functions as not only a fatty acid translocase but also a scavenger receptor type- $\mathrm{B}$ in a range of normal and pathological processes. ${ }^{31-33}$ Interestingly, CD36 expression was not detected in the hepatic foamy macrophages of the $\mathrm{RD}+$ oxLDL group but was prominently detected on the hepatic macrophages of RD-fed mice immediately after oxLDL injection (Figures $6 \mathrm{c}$ and d). Moreover, our in vitro analysis by confocal microscopy also showed rapid and transient upregulation of CD36 on the plasma membrane of macrophages after stimulation with oxLDL, whereas its gene expression in the cells increased in a time-dependent manner (Figures $7 \mathrm{~b}$ and $\mathrm{c}$ ). These results suggest that the rapid modulation of CD36 in response to oxLDL was due to the pre-synthesized protein sorting to the membrane but was not related to new protein synthesis. It was reported that macrophage CD36 takes up oxLDL through a non-caveolar, lipid raft-mediated pathway. ${ }^{54}$ However, the reason for this rapid modulation is not yet clear. Thus, further investigation is required to understand CD36 localization and translocation in macrophages. In this study, we further found that oxLDL also upregulated the mRNA levels of PPAR- $\gamma$ and CD36, as well as CD36 protein expression, in the hepatocytes of HFD + oxLDL mice, although these changes were not observed in RD + oxLDL mice (Figures $6 \mathrm{a}-\mathrm{c}$ ). Similarly, a recent study by Truong et al $^{56}$ showed CD36 overexpression on the plasma membrane in response to oxLDL in a human hepatocyte cell line, which is dependent on the presence of lipid rafts and caveolae. Thus, we conclude that CD36 mediates the pathophysiology of NASH in different liver cells, which may be regulated by distinct mechanisms.

Figure 7 Effects of oxLDL on foam cell formation and CD36 expression in macrophages. (a) Murine peritoneal macrophages were exposed to $250 \mu \mathrm{g} / \mathrm{ml}$ oxLDL for $24 \mathrm{~h}$ or left untreated, and stained with oil-red O. No lipid droplets were stained in the untreated cells. Intracytoplasmic lipid accumulation and foam cell formation were observed in the oxLDL-treated cells (original magnification, $\times 400$ ). (b) The time course of CD36 mRNA expression in macrophages in response to oxLDL is shown. Data are expressed as the mean \pm s.d. of three separate experiments. ${ }^{\star P}<0.01 ;{ }^{*} P<0.001$. (c) Confocal microscopic analysis showed a rapid and transient increase in CD36 expression on the plasma membrane of macrophages after oxLDL stimulation (original magnification, $\times 400$ ). 
In summary, our study implicates HFD and oxLDL in the initiation of NASH pathogenesis. An increased oxidative state, including HFD-induced intracellular lipid peroxidation and an extracellular source from oxLDL, had a crucial role in induction of hepatic steatohepatitis, which was mainly mediated by TNF- $\alpha$ and IL- 6 in this model. Furthermore, our results also provide new evidence that CD36 expressed on hepatocytes and hepatic macrophages in response to HFD and oxLDL contributes to the pathogenic processes of NASH, which may have important implications for NASH therapies.

\section{ACKNOWLEDGEMENT}

This study was supported by Sapporo Biocluster 'Bio-S', the Regional Innovation Cluster Program, and the Ministry of Education, Culture, Sports, Science and Technology, Japan.

\section{DISCLOSURE/CONFLICT OF INTEREST}

The authors declare no conflict of interest.

1. Adams LA, Feldstein AE. Non-invasive diagnosis of nonalcoholic fatty liver and nonalcoholic steatohepatitis. J Dig Dis 2011;12:10-16.

2. Marchesini G, Bugianesi E, Forlani G, et al. Nonalcoholic fatty liver, steatohepatitis, and the metabolic syndrome. Hepatology 2003;37:917-923.

3. Erickson SK. Nonalcoholic fatty liver disease. J Lipid Res 2009;50: S412-S416.

4. Carter-Kent C, Zein NN, Feldstein AE. Cytokines in the pathogenesis of fatty liver and disease progression to steatohepatitis: implications for treatment. Am J Gastroenterol 2008;103:1036-1042.

5. Diehl AM. Lessons from animal models of NASH. Hepatol Res 2005;33:138-144.

6. Kirsch R, Clarkson V, Shephard EG, et al. Rodent nutritional model of non-alcoholic steatohepatitis: species, strain and sex difference studies. J Gastroenterol Hepatol 2003;18:1272-1282.

7. Day CP, James OF. Steatohepatitis: a tale of two 'hits'? Gastroenterology 1998;114:842-845.

8. Haque JA, McMahan RS, Campbell JS, et al. Attenuated progression of diet-induced steatohepatitis in glutathione-deficient mice. Lab Invest 2010;90:1704-1717.

9. Yamaguchi K, Yang L, McCall $\mathrm{S}$, et al. Inhibiting triglyceride synthesis improves hepatic steatosis but exacerbates liver damage and fibrosis in obese mice with nonalcoholic steatohepatitis. Hepatology 2007:45:1366-1374.

10. Shoelson SE, Herrero L, Naaz A. Obesity, inflammation, and insulin resistance. Gastroenterology 2007;132:2169-2180.

11. Bieghs V, Wouters $K$, van Gorp PJ, et al. Role of scavenger receptor A and CD36 in diet-induced nonalcoholic steatohepatitis in hyperlipidemic mice. Gastroenterology 2010;138:2477-2486.

12. Jou J, Choi SS, Diehl AM. Mechanisms of disease progression in nonalcoholic fatty liver disease. Semin Liver Dis 2008;28:370-379.

13. Anstee $\mathrm{QM}$, Goldin RD. Mouse models in non-alcoholic fatty liver disease and steatohepatitis research. Int J Exp Pathol 2006;87:1-16.

14. Mohanty $\mathrm{P}$, Ghanim $\mathrm{H}$, Hamouda $\mathrm{W}$, et al. Both lipid and protein intakes stimulate increased generation of reactive oxygen species by polymorphonuclear leukocytes and mononuclear cells. Am J Clin Nutr 2002;75:767-772.

15. Hansson GK. Inflammation, atherosclerosis, and coronary artery disease. N Engl J Med 2005;352:1685-1695.

16. Dje N'Guessan P, Riediger F, Vardarova K, et al. Statins control oxidized LDL-mediated histone modifications and gene expression in cultured human endothelial cells. Arterioscler Thromb Vasc Biol 2009;29: 380-386.

17. Asmis R, Begley JG, Jelk J, et al. Lipoprotein aggregation protects human monocyte-derived macrophages from oxLDL-induced cytotoxicity. J Lipid Res 2005;46:1124-1132.

18. Salvayre R, Auge N, Benoist $H$, et al. Oxidized low-density lipoproteininduced apoptosis. Biochim Biophys Acta 2002;1585:213-221.
19. Maziere C, Meignotte A, Dantin F, et al. Oxidized LDL induces an oxidative stress and activates the tumor suppressor p53 in MRC5 human fibroblasts. Biochem Biophys Res Commun 2000;276: 718-723.

20. Gambino R, Musso G, Cassader M. Redox balance in the pathogenesis of nonalcoholic fatty liver disease: mechanisms and therapeutic opportunities. Antioxid Redox Signal 2011;15:1325-1365.

21. Clark JM. The epidemiology of nonalcoholic fatty liver disease in adults. J Clin Gastroenterol 2006;40:S5-S10.

22. Takahashi $\mathrm{Y}$, Chiba $\mathrm{H}$, Matsuno $\mathrm{K}$, et al. Native lipoproteins inhibit platelet activation induced by oxidized lipoproteins. Biochem Biophys Res Commun 1996;222:453-459.

23. Markwell MA, Haas SM, Bieber LL, et al. A modification of the Lowry procedure to simplify protein determination in membrane and lipoprotein samples. Anal Biochem 1978;87:206-210.

24. Yagi K. Lipid peroxides and human diseases. Chem Phys Lipids 1987;45:337-351.

25. Kleiner DE, Brunt EM, Van Natta $M$, et al. Design and validation of a histological scoring system for nonalcoholic fatty liver disease. Hepatology 2005;41:1313-1321.

26. Folch J, Lees M, Sloane-Stanley GH. A simple method for the isolation and purification of total lipids from animal tissues. J Biol Chem 1957;226:497-509.

27. Yimin, Kohanawa M. A regulatory effect of the balance between TNF- $\alpha$ and IL-6 in the granulomatous and inflammatory response to Rhodococcus aurantiacus infection in mice. J Immunol 2006;177: 642-650.

28. Wu CW, Yu J. Molecular basis for a functional role of cytochrome P450 2E1 in non-alcoholic steatohepatitis. J Gastroenterol Hepatol 2010;25:1019-1020.

29. Yamaguchi K, Itoh Y, Yokomizo C, et al. Blocked of IL-6 signaling exacerbates liver injury and suppresses antiapoptotic gene expression in methionine choline-deficient diet-fed $\mathrm{db} / \mathrm{db}$ mice. Lab Invest 2011;91:609-618.

30. Fraser DA, Tenner AJ. Innate immune proteins $\mathrm{C} 1 \mathrm{q}$ and mannanbinding lectin enhance clearance of atherogenic lipoproteins by human monocytes and macrophages. J Immunol 2010;185:3932-3939.

31. Su X, Abumrad NA. Cellular fatty acid uptake: a pathway under construction. Trends Endocrinol Metab 2009;20:72-77.

32. Febbraio M, Hajjar DP, Silverstein RL. CD36: a class B scavenge receptor involved in angiogenesis, atherosclerosis, inflammation, and lipid metabolism. J Clin Invest 2001;108:785-791.

33. Nicholson AC, Hajjar DP. CD36, oxidized LDL and PPAR $\gamma$ : Pathological interactions in macrophages and atherosclerosis. Vascul Pharmacol 2005;41:139-146.

34. Berk PD. Regulatable fatty acid transport mechanisms are central to the pathophysiology of obesity, fatty liver, and metabolic syndrome. Hepatology 2008;48:1362-1376.

35. Zhou J, Febbraio M, Wada T, et al. Hepatic fatty acid transporter Cd36 is a common target of LXR, PXR, and PPARgamma in promoting steatosis. Gastroenterology 2008;134:556-567.

36. $\mathrm{Yu} \mathrm{S}$, Matsusue $\mathrm{K}$, Kashireddy $\mathrm{P}$, et al. Adipocyte-specific gene expression and adipogenic steatosis in the mouse liver due to $\begin{array}{llll}\text { peroxisome proliferator-activated receptor } \gamma 1 & \text { (PPAR } \gamma 1)\end{array}$ overexpression. J Biol Chem 2003;278:498-505.

37. Ehehalt R, Füllekrug J, Pohl J, et al. Translocation of long chain fatty acids across the plasma membrane-lipid rafts and fatty acid transport proteins. Mol Cell Biochem 2006;284:135-140.

38. Miquilena-Colina $M E$, Lima-Cabello $E$, Sanchez-Campos $S$, et al. Hepatic fatty acid translocase CD36 upregulation is associated with insulin resistance, hyperinsulinaemia and increased steatosis in non-alcoholic steatohepatitis and chronic hepatitis C. Gut 2011;60: 1394-1402.

39. Greco D, Kotronen A, Westerbacka J, et al. Gene expression in human NAFLD. Am J Physiol Gastrointest Liver Physiol 2008;294:1281-1287.

40. Fisher CD, Lickteig AJ, Augustine LM, et al. Hepatic cytochrome P450 enzyme alterations in humans with progressive stages of nonalcoholic fatty liver disease. Drug Metab Dispos 2009;37:2087-2094.

41. Farrell GC, Larter CZ. Nonalcoholic fatty liver disease: from steatosis to cirrhosis. Hepatology 2006;43:S99-S112.

42. Lanthier N, Molendi-Coste O, Horsmans $\mathrm{Y}$, et al. Kupffer cell activation is a causal factor for hepatic insulin resistance. Am J Physio Gastrointest Liver Physiol 2010;298:G107-G116. 
43. Huang W, Metlakunta A, Dedousis N, et al. Depletion of liver Kupffer cells prevents the development of diet-induced hepatic steatosis and insulin resistance. Diabetes 2010;59:347-357.

44. Tomita K, Tamiya G, Ando S, et al. Tumour necrosis factor alpha signalling through activation of Kupffer cells plays an essential role in liver fibrosis of non-alcoholic steatohepatitis in mice. Gut 2006;55: 415-424.

45. Comporti M, Arezzini B, Signorini C, et al. F2-isoprostanes stimulate collagen synthesis in activated hepatic stellate cells: a link with liver fibrosis? Lab Invest 2005;85:1381-1391.

46. Samoilova EB, Horton JL, Hilliard B, et al. IL-6-deficient mice are resistant to experimental autoimmune encephalomyelitis: roles of IL-6 in the activation and differentiation of autoreactive T cells. J Immuno 1998;161:6480-6486.

47. Wieckowska A, Papouchado BG, Li Z, et al. Increased hepatic and circulating interleukin-6 levels in human nonalcoholic steatohepatitis. Am J Gastroenterol 2008;103:1372-1379.

48. Kennedy DJ, Kuchibhotla S, Westfall KM, et al. A CD36dependent pathway enhances macrophage and adipose tissue inflammation and impairs insulin signalling. Cardiovasc Res 2011;89: 604-613.

49. Okajima F, Kurihara M, Ono $C$, et al. Oxidized but not acetylated lowdensity lipoprotein reduces preproinsulin mRNA expression and secretion of insulin from HIT-T15 cells. Biochim Biophys Acta 2005; 1687:173-180.

50. Han CY, Pak YK. Oxidation-dependent effects of oxidized LDL proliferation or cell death. Exp Mol Med 1999;31:165-173.

51. Ota $T$, Takamura $T$, Kurita $S$, et al. Insulin resistance accelerates a dietary rat model of nonalcoholic steatohepatitis. Gastroenterology 2007;132:282-293.

52. Shiri-Sverdlov R, Wouters K, van Gorp PJ, et al. Early diet-induced nonalcoholic steatohepatitis in APOE2 knock-in mice and its prevention by fibrates. J Hepatol 2006;44:732-741.

53. Kunjathoor VV, Febbraio M, Podrez EA, et al. Scavenger receptors class $\mathrm{A}-\mathrm{I} / \mathrm{II}$ and CD36 are the principal receptors responsible for the uptake of modified low density lipoprotein leading to lipid loading in macrophages. J Bio Chem 2002;277:49982-49988.

54. Sun B, Boyanovsky BB, Connelly MA, et al. Distinct mechanisms for OxLDL uptake and cellular trafficking by class $B$ scavenger receptors CD36 and SR-BI. J Lipid Res 2007;48:2560-2570.

55. Ferreira V, van Dijk KW, Groen AK, et al. Macrophage-specific inhibition of NF-kappaB activation reduces foam-cell formation. Atherosclerosis 2007;192:283-290.

56. Truong TQ, Brodeur MR, Falstrault L, et al. Expression of caveolin-1 in hepatic cells increases oxidized LDL uptake and preserves the expression of lipoprotein receptors. J Cell Biochem 2009;108:906-915. 